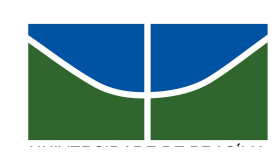

UNIVERSIDADE DE BRASÍLIA

Centro de Excelência em Turismo

Pós-graduação Lato Sensu

Curso de Especialização em Gastronomia e Saúde

\title{
AVALIAÇÃO QUALITATIVA DAS PREPARAÇÕES DIVULGADAS NO FESTIVAL BRASIL SABOR BRASÍLIA - FESTIVAL GASTRONÔMICO DE 2007
}

\author{
Luciana Carvalho de Carvalho
}

MSc. Verônica Ginani

Brasília - 2008 


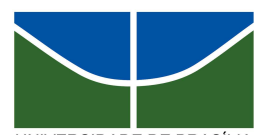

UNIVERSIDADE DE BRASÍLIA

Centro de Excelência em Turismo

Pós-graduação Lato Sensu

Curso de Especialização em Gastronomia e Saúde

\section{AVALIAÇÃO QUALITATIVA DAS PREPARAÇÕES DIVULGADAS NO FESTIVAL BRASIL SABOR BRASÍLIA - FESTIVAL GASTRONÔMICO DE 2007}

Luciana Carvalho de Carvalho

MSc. Verônica Ginani

Monografia apresentada ao Centro de Excelência em Turismo - CET, da Universidade de Brasília UnB, como requisito parcial à obtenção do grau de Especialista em Gastronomia e Saúde.

Brasília - 2008 


\section{Carvalho, Luciana Carvalho de.}

Avaliação qualitativa das preparações do Festival Brasil Sabor Brasília: festival gastronômico de 2007 / Luciana Carvalho de Carvalho. - Brasília, 2008.

$$
\text { vi, } 57 \text { f. : il. color.; } 30 \mathrm{~cm} \text {. }
$$

Monografia (especialização) - Universidade de Brasília, Centro de Excelência em Turismo, 2008.

Orientador: Verônica Ginani.

1. Alimento. 2. Gastronomia. 3. Festival Gastronômico. I. Título.

II. Título: festival gastronômico de 2007. 
UNIVERSIDADE DE BRASÍLIA

Centro de Excelência em Turismo

Pós-graduação Lato Sensu

Curso de Especialização em Gastronomia e Saúde

\section{Luciana Carvalho de Carvalho}

Aprovado por:

Professor orientador: MSc. Verônica Ginani

Professor: Dra. Raquel Braz Assunção Botelho

Professor: Dra. Karin Eleonora Sávio de Oliveira

Brasília, 08 de agosto de 2008. 


\section{RESUMO}

O presente documento vem apresentar fatos em relação à alimentação saudável, que reconhecidamente auxilia na prevenção de doenças crônico não-transmissíveis. A gastronomia, cada vez mais presente na vida das pessoas, não poderia ignorar esta relação, participando com receitas/alimentos mais saudáveis e sensorialmente adequadas. Como a gastronomia esta em voga, surgiram os festivais gastronômicos, que são realizados em várias localidades, visando uma conseqüente valorização cultural, entre outros benefícios. Eventos que envolvem alimentação deveriam estar atentos a incluírem em sua programação receitas/alimentos mais saudáveis. Pois estas podem vir a ser incluídas no cardápio comercial dos estabelecimentos participantes. Com o objetivo de analisar qualitativamente as preparações ofertadas durante o Festival Brasil Sabor Brasília 2007, esta pesquisa utilizou o método AQPC, analisando 25 preparações. Verificou-se, negativamente, monotonia do cardápio, reduzida variação de cores e emprego excessivo de alimentos gordurosos. Contudo, positivamente, observou-se que as técnicas de cocção empregadas em $40 \%$ das receitas, não privilegiavam o uso de gordura, o que contribui para o equilíbrio nutricional das preparações ofertadas. Identificou-se, portanto, que existe uma tendência na utilização de técnicas de preparo com isenção de gordura, mas os efeitos gastronômicos deste ingrediente continuam sendo valorizados e empregados pelos chefes de cozinha. Para os próximos festivais, a utilização de hortaliças e frutas deve ser estimulada, potencializando, assim, a promoção da saúde por meio da alimentação.

Palavras-chave: Alimento. Alimentação saudável. Gastronomia. Festival Gastronômico. 


\begin{abstract}
The present paper deals with questions related to healthy nourishment, which recognizedly contributes to preventing non-transmittable chronic diseases. It is essential that gastronomy, being ever more present in the lives of individuals, take this relation into account by offering healthier, more appetizing recipes/dishes. Since gastronomy is now in vogue, food festivals have come to be organized in various locales with a view to cultural enrichment, among other advantages. However, events involving food should be attentive to including healthier recipes/dishes in their programs. With the objective of qualitatively analyzing the offerings presented at the 2007 Tastes of Brasília Gastronomic Festival, the AQPC method was used in the present research. On the negative side, the menu was monotonous, the variety of colors limited and the foods excessively fatty. On the positive side, $40 \%$ of the recipes employed fat-free cooking techniques, thus contributing to the nutritional balance of the dishes offered. However, despite the trend in the direction of fat-free techniques, the gastronomic effects of the ingredient continue to be valued and employed by the chefs. In future festivals, the use of fruit and vegetables should therefore be stimulated, thus promoting health through proper nourishment.
\end{abstract}

Keywords: Food. Healthy nourishment. Gastronomy. Gastronomic festival. 


\section{SUMÁRIO}

1 INTRODUÇÃO

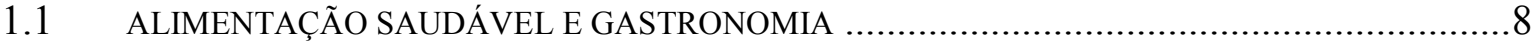

1.2 GASTRONOMIA, TURISMO E EVENTOS ................................................................

1.3 FESTIVAL BRASIL SABOR BRASILIA .................................................................13

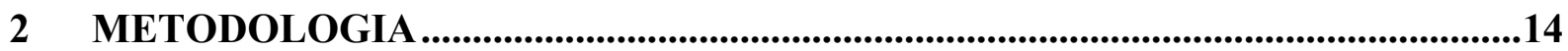

3 RESULTADOS E DISCUSSÃO_...................................................................15

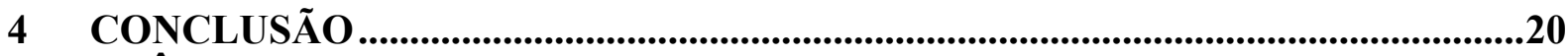

REFERÊNCIAS.................................................................................................................21

APÊNDICE A - FICHAS TÉCNICAS DAS PREPARAÇÕES .............................................23

APÊNDICE B - AVALIAÇÃO QUALITATIVA DAS PREPARAÇÕES............................48

APÊNDICE C - RESULTADOS OBTIDOS ATRAVÉS DA AVALIAÇÃO......................53 


\section{INTRODUÇÃO}

\subsection{Alimentação saudável e gastronomia}

A alimentação saudável é hoje considerada condição para se ter uma vida sem doenças e prolongada. $\mathrm{O}$ aumento de consumo de frutas e hortaliças é um dos princípios básicos para isto, aliada a saúde física e mental (OMS, 2002).

Difundiu-se por pesquisadores da área nutricional que uma boa alimentação assegura não só um crescimento e um desenvolvimento normais, mas aumenta a resistência às doenças, possibilitando a prevenção das doenças crônicas não-transmissíveis (DCNT’s) e o câncer. Também pode ser responsável pelo retardo do envelhecimento, por assegurar o bem estar mental e proteger o homem contra as toxinas do ambiente (PROENÇA, VEIROS 2005).

Através de estudos epidemiológicos, sugerem-se correlações positivas entre algumas doenças e dieta rica em gorduras (saturadas, colesterol e trans), sal, alimentos refinados e alta concentração de açúcar, baixa ingestão de fibras, bem como elevado consumo de carnes vermelhas, bebida alcoólica, somada ao tabagismo e sedentarismo. Decorrente de dietas com tais características, a prevalência da obesidade e alterações do perfil lipídico podem resultar no desenvolvimento de DCNT's como hipertensão arterial, diabetes, doenças cardiovasculares, câncer entre outras (OLIVEIRA et al., 2004; PINHEIRO et al., 2004).

A Organização Mundial da Saúde (2002) sugere que o conteúdo de gordura na alimentação das pessoas saudáveis não exceda $30 \%$ da ingestão calórica. Também é recomendado que menos de $10 \%$ das calorias sejam provenientes de ácidos graxos saturados (carne, leite, manteiga, queijo, vegetais gordurosos e alguns grãos processados) e que a quantidade de colesterol na alimentação seja menor que 300mg/dia. Em relação ao consumo de sódio, conforme o Ministério da Saúde (1999) sugere um consumo não superior a $1,7 \mathrm{~g}$ de sódio ( $5 \mathrm{~g}$ de cloreto de sódio) por dia, como benéfico para a redução da pressão arterial. E todo o sal para consumo humano deve ser iodado.

A alimentação cumpre uma função biológica ao fornecer ao corpo as substâncias indispensáveis para sua subsistência. Levando-se em conta os fatores biológicos relacionados com o sistema digestório e as necessidades básicas de um organismo para a sua sobrevivência, faz-se necessário uma dieta equilibrada, que contemple a ampla gama de alimentos disponíveis tanto de procedência animal como vegetal. Assim mesmo, há fatores genéticos hereditários relacionados com a intolerância a determinados alimentos (OMS, 2002). 
Renomados pesquisadores como Poulain (2004), consideram que o alimento apresenta um significado simbólico para os indivíduos. As práticas alimentares, que envolvem os procedimentos de preparo até o seu consumo são repletas de subjetividade, que inclui a forma como tais práticas são percebidas por cada pessoa segundo a identidade cultural, a condição socioeconômica, os valores religiosos, e a memória familiar desde a infância até a idade atual.

No contexto de alimentação saudável, portanto, esses fatores devem ser considerados. Dessa forma o Ministério da Saúde orienta que a alimentação não se delineia enquanto uma receita preconcebida e universal para todos. Deve respeitar alguns atributos coletivos e individuais impossíveis de serem quantificados de maneira prescrita. Contudo, relacionandose alimentação e saúde, identificam-se alguns princípios básicos: variedade - comer diferentes tipos de alimentos dos diversos grupos, com qualidade comprovada; moderação - comer nem mais e nem menos do que o organismo precisa e equilíbrio - quantidade e qualidade são importantes e consumir alimentos variados (MS, 1999).

A alimentação é uma necessidade básica do ser humano. Portanto, sempre acompanhou o homem em sua evolução e, por isso, traz marcas do passado, da história, da sociedade, do povo e da nação à qual pertence. $\mathrm{O}$ homem não come somente para saciar a fome, mas também para ter prazer. A gastronomia representa não só os hábitos culturais de um povo, mas, sim toda sua história e tradição. Refere-se à perpetuação da espécie, devendo garantir a saúde do ser humano.

Nas citações de Franco (2001), quando o homem aprendeu a cozinhar os alimentos, surgiu uma profunda diferença entre ele e os animais. Ao cozinhar o homem descobre que o alimento pode proporcionar maior prazer, além de ter uma digestão mais facilitada, gerando bem estar durante o ato da alimentação e posteriormente, também.

O homem ampliou a variedade de alimentos com o cultivo da terra, há cerca de dez mil anos. A agricultura surgiu quando o homem se absteve de consumir parte dos grãos colhidos e os enterrou para que germinassem e se multiplicassem. Começaria, posteriormente, a domesticar alguns dos animais que antes caçava (FRANCO, 2001).

Muito diferente das outras artes, a gastronomia não é estática. A história de sua evolução varia de acordo com as áreas geográficas e as épocas. Todas as transformações da economia, políticas e estrutural de um determinado local influenciam nos hábitos e tradições culinárias do mesmo (FRANCO, 2001). 


\subsection{Gastronomia, turismo e eventos}

Por outro lado, a gastronomia é considerada na atualidade motivadora de diferentes atividades. Definida como tudo que se refere ao homem à medida que se alimenta (SAVARIN, 1999), além de representar hábitos e estilos de vida, pode ser razão primária e secundária para a ocorrência de deslocamentos, como no caso do turismo, projetos que envolvam questões políticas, econômicas, ambientais, entre outros.

A gastronomia tradicional e as práticas turísticas associadas fomentam a cultura de produtos tradicionais, proporcionam o escoamento de produtos agrícolas, geram emprego, a nível local, contribuem para o desenvolvimento econômico, ajudam a combater a desertificação das regiões menos favorecidas e potencializam e complementam os recursos existentes (SCHLUTER,2003).

Segundo a EMBRATUR (2004), a gastronomia estaria vinculada a um Patrimônio Imaterial junto com todos os outros bens que de alguma forma criam, constroem, ou interferem no desenvolvimento natural da vida sobre a terra e que com o passar do tempo são modificadas pelo processo de recriação coletiva. Pode-se citar como exemplo além da culinária, as famosas festas populares e religiosas, o folclore Brasileiro, artesanato, saberes e lazeres, que são reconhecidos pela sociedade com seus valores mais expressivos, que atuam como grandes atrativos turísticos.

A gastronomia é um componente importante da oferta de um destino turístico, pois todos os turistas necessitam de se alimentar. Podendo tratando-se da principal motivação ou de uma simples necessidade, a gastronomia pode ter um elevado peso no consumo efetuado pelos turistas.

Para que a gastronomia atue como vetor da promoção turística, terá que ser desenvolvido um conjunto de ações, nomeadamente:

- transmitir aos turistas as origens e meios de confeccionar os pratos tradicionais;

- relacionar a gastronomia com a história e cultura de uma região;

- criar a possibilidade de se estabelecer contacto entre o turista, consumidor final, e o produtor;

- dar a possibilidade aos operadores turísticos, agentes de viagens e líderes de opinião de saborearem a genuína gastronomia, através da realização de:

- visitas a restaurantes e outros estabelecimentos hoteleiros e de restauração;

- mostras e provas gastronômicas; 
- mostras e provas de produtos certificados.

Segundo Bóia (2001), esses eventos gastronômicos atraem turistas em busca do prazer pelo paladar. O público para esse tipo de eventos independe de idade, sexo, raça, origem ou condição física. No entanto, é importante focar o público correto, pois para o sucesso efetivo do evento a delimitação de um público-alvo preciso é essencial, pois irá ampliar o grau de relacionamento e de convivência, otimizando os resultados do acontecimento, existente entre os participantes (MEIRELLES, 1999).

Eventos gastronômicos, então, constituem um negócio promissor, pois possui um público apreciador bastante vasto, ampliando possibilidades para os empresários que se aventuram no ramo. Além, de economicamente vantajoso possui um caráter social de grande relevância, uma vez que promove a valorização da cultura de uma determinada população.

A gastronomia é um elemento cultural que demonstra os hábitos e origens de uma localidade turística. Sendo assim, a realização de eventos gastronômicos seria uma representação da cultura de um determinado local, mesclas de demonstração cultural e atrativo de lazer.

A gastronomia que está cada vez mais difundida é uma área importante para que se façam estudos e pesquisas com os alimentos com o intuito de apresentar receitas/preparações mais saudáveis e sensorialmente adequadas.

Com a evolução da gastronomia, o aumento na diversidade de restaurantes, receitas, cursos, roteiros turísticos voltados para a alimentação é crescente e notória. Neste contexto, os festivais gastronômicos aparecem com uma oportunidade de converter cidades em localidades turísticas importantes. Buscam transformar receitas/preparações culinárias regionais em atrativos turísticos, assim como valorizam chefes, restaurantes e regiões ou cidades específicas. Destacam-se a identidade e a cultura como forma de potencializar as atividades turísticas de determinada região.

Outra questão relevante apresentada pelos festivais, se refere a influência das receitas divulgadas exercida sob o meio gastronômico. As técnicas utilizadas, assim como a origem de ingredientes quando avaliadas positivamente, passam a compor cardápios de restaurantes variados. Exemplifica esta situação, o evento da rede Terra Madre que acontece com o Salone del Gusto (Salão do Gosto) e integram o movimento do slow food. O encontro tem como público-alvo comunidades do alimento, chefes de cozinha, docentes e jovens de toda nacionalidade. O objetivo principal é promover uma produção alimentar local, sustentável e respeitosa dos métodos herdados e consolidados no tempo(SLOW FOOD - BRASIL, 2008). 
Como resultado do empenho exercido pelos participantes do Terra Madre, observa-se em todo o mundo, vários estabelecimentos gastronômicos que defendem a filosofia do movimento. Oficialmente, no Brasil, são 8 (oito) chefes que compõem a rede Terra Madre. Colocam em seus cardápios preparações que respeitam os princípios do slow food, e aumentam o número de adeptos ao movimento (SLOW FOOD - BRASIL, 2008).

Respeitando-se as devidas proporções, uma vez que o Terra Madre possui dimensão internacional e relaciona-se a um movimento que determina um estilo de vida, outros festivais também podem exercer influência no consumo de alimentos.

Considerando que o comer fora de casa é uma realidade em grandes centros urbanos, os cardápios utilizados em festivais, com boa aceitação e que podem ser perpetuados nos restaurantes, devem ser analisados em sua totalidade. A alimentação saudável não deve ser negligenciada em prol exclusivamente do prazer. É importante que se pondere sobre a relação alimento e saúde, identificando nas recomendações da Organização Mundial de Saúde (OMS, 2002), estratégias a serem aplicadas na criação e elaboração das receitas.

Explicada pelo estilo de vida do homem moderno citadino, a comensalidade contemporânea se caracteriza "pela escassez de tempo para o preparo e consumo de alimentos; pela presença de produtos gerados com novas técnicas de conservação e preparo, que agregam tempo e trabalho; pelo vasto leque de itens alimentares; pelos deslocamentos das refeições de casa para estabelecimentos que comercializam alimentos (restaurantes, lanchonetes, vendedores ambulantes, padarias entre outros); pela crescente oferta de preparações e utensílios transportáveis; pela oferta de produtos provenientes de várias partes do mundo; pelo arsenal publicitário associado aos alimentos; pela flexibilização de horários para comer juntamente com a diversidade de alimentos e pela crescente individualização dos rituais alimentares" (Garcia, 2003: p. 484).

Atualmente, há infinidade de festivais gastronômicos acontecendo em várias cidades do Brasil, cada um com um tema e características diferenciados, visando a divulgação da cultura e da gastronomia popular local. Como inúmeros sites e blogs da internet e revistas com publicações mensais, tais como Correio Gourmand, Brasil Sabor, Quero Comer, Gula, Menu, Alta Gastronomia e muitos outros. 


\subsection{Festival Brasil Sabor}

Nos últimos anos, tem-se observado uma grande expansão de mercado no que se refere a festival gastronômico e ao fascínio que a culinária exerce sobre os turistas e a população de forma geral. Este fascínio tem sido o tempero fundamental para uma receita de sucesso que a Abrasel - Associação Brasileira de Bares e Restaurantes está desenvolvendo em parceria com o Ministério do Turismo e o SEBRAE: o Movimento Brasil Sabor. Uma ação que busca a valorização e promoção da gastronomia brasileira como um grande diferencial competitivo para o setor de turismo no país (ABRASEL, 2007).

O Movimento Brasil Sabor é constituído por um conjunto de ações estratégicas com resultados muito positivos e que tem como base investimentos na qualificação para o alimento seguro, melhoria dos serviços prestados e promoção da gastronomia brasileira.

Uma das ações de destaque do Movimento Brasil Sabor é a realização do maior festival gastronômico do planeta, por ser realizado em várias cidades do Brasil ao mesmo tempo, o Brasil Sabor. Em 2007, em sua segunda edição, o festival mobilizou, simultaneamente, 1.528 restaurantes, em 177 destinos turísticos, de 26 estados do país. Foi novamente uma ótima oportunidade para se provar a rica gastronomia do Brasil (ABRASEL, 2008).

Em sua terceira edição, 2008, não poderia ser diferente. Teve a participação de cerca de 2000 restaurantes nos quatro cantos do país. O Festival demonstra que além de seus belos roteiros turísticos e de sua valiosa cultura, o Brasil possui uma riqueza única: a gastronomia. Além disso, comprova que com sua variedade de ingredientes, temperos, aromas, cores e sabores a culinária brasileira é, sem dúvida, um dos importantes atrativos turísticos que o Brasil tem a oferecer.

Em Brasília, o Festival Brasil Sabor Brasília - Festival Gastronômico, já vinha sendo realizado, mas com outro nome e outra roupagem, sendo em 2006 inserido no Movimento Brasil Sabor, e realizado o primeiro ano do festival em homenagem aos 20 anos da Abrasel e o mesmo tornando-se nacional. Participaram 50 restaurantes, com duração de 18 dias. No ano de 2007, 69 restaurantes participaram e teve duração de 36 dias. Em 2008 foram, 57 restaurantes participantes, com duração do evento de 30 dias. Cada restaurante apresenta uma receita/preparação que é elaborada para o festival e com ingredientes regionais e custo diferenciado, para dar maior visibilidade ao evento gastronômico. Sendo montados livros com a coletânea de pratos apresentados durante o festival. No momento foram publicados os pratos 
elaborados dos restaurantes participantes, somente dos anos de 2006 e 2007 (ABRASEL,2008).

O objetivo desta pesquisa é analisar as receitas/preparações apresentadas pelos restaurantes participantes sob a perspectiva da saúde. Procurou-se identificar se as preparações são saudáveis, estimulando o consumo de hortaliças, alimentos e técnicas de cocção com menor teor de gorduras.

\section{METODOLOGIA}

A pesquisa realizada é do tipo exploratória. Buscou-se verificar a relação entre as preparações/receitas apresentadas pelos restaurantes participantes do Festival Brasil Sabor Brasília 2007 em relação a qualidade nutricional e sensorial das mesmas.

Foi utilizado como referência o Livro Segredos dos Chefes do Festival de 2007, que apresenta 69 preparações, das quais 25 foram selecionadas para análise, uma vez que as fichas técnicas de preparo das demais não apresentavam dados suficientes para o estudo. Verificando-se, então as respectivas fichas técnicas de preparo - FTP, foi realizada a Avaliação Qualitativa das Preparações (APÊNDICE A).

Buscando analisar os itens pertinentes a uma avaliação qualitativa de um cardápio, levando em consideração aspectos fundamentais como os nutricionais e os sensoriais, que surgiu o método AQPC - Avaliação Qualitativa das Preparações de um Cardápio, proposto por Veiros e Proença (2003). Para o presente estudo, como se tratava de uma modalidade não contemplada pelo método, foi realizada uma adaptação, considerando as preparações de forma individual e também em um contexto global (PROENÇA; VEIROS, 2003).

O método auxilia na percepção do equilíbrio em aspectos tais como tipos, cores, formas de preparo dos alimentos, presença de frutas entre outros, tentando tornar a refeição mais atrativa para os comensais, sempre buscando um consumo mais saudável. Facilita o profissional, geralmente o nutricionista ou o gastrônomo, na elaboração de um cardápio mais adequado nutricionalmente e com alguns aspectos sensoriais (PROENÇA; VEIROS, 2003).

A análise foi realizada através de uma tabela com cinco partes, verificando o tipo de preparação (prato principal, guarnição, entrada, acompanhamento, sobremesa), técnica de cocção, cor, presença de hortaliças e ingredientes com gordura. Após foram feitos os somatórios e as porcentagens destes dados das preparações (APÊNDICE B e C). 


\section{RESULTADOS E DISCUSSÃO}

Em relação aos pratos principais e pratos únicos utilizados pelos 25 restaurantes analisados, apresenta-se o gráfico abaixo, que mostra os corte de carnes mais utilizados e outros pratos únicos apresentados.

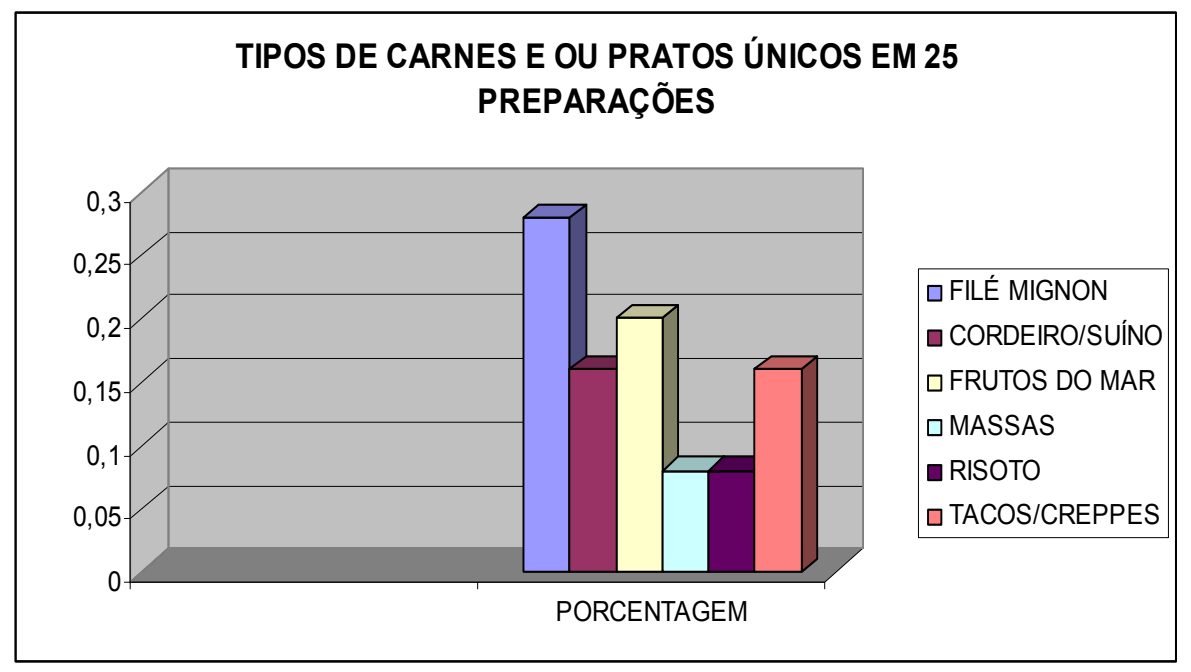

Gráfico 1: Tipos de carnes e ou pratos únicos em 25 preparações

Analisando-se os cortes de carnes, segundo Araújo et al (2007), contêm elevada concentração de água livre, proteínas, lipídios e cinzas, entre outros. Certa fração protéica, formada pela actina e miosina, é importante porque está associada à capacidade de retenção de água, que afeta a maciez, a suculência e agem diretamente nas características sensoriais das mesmas. Entre os cortes selecionados, observa-se que as características citadas foram privilegiadas. Buscaram-se, provavelmente, cortes com maior maciez e, portanto, maior aceitação pelo público. Positivamente, nota-se a utilização de alguns cortes de carnes com baixo teor de gordura (TABELA 1 e 2), como no caso do filé mignon e alguns pescados. No entanto, outros cortes, como o de suínos e cordeiros, apesar de teor lipídico elevado, quando presentes no cardápio, poderiam estar acompanhados de guarnições com hortaliças, o que conforme o apêndice (II) não pôde ser verificado.

Tabela 1: Composição do tecido muscular magro (em\%)

\begin{tabular}{ccccc}
\hline Espécie & Água & Proteína & Lipídio & Cinza \\
\hline Bovinos & $70-73$ & $20-22$ & $4-8$ & 1 \\
Suínos & $68-70$ & $19-20$ & $9-11$ & 1,4 \\
Aves & 73,7 & $20-23$ & $4-7$ & 1 \\
Cordeiro & 73 & 20 & $5-6$ & 1,6 \\
Bacalhau & 81,2 & 17,6 & 0,3 & 1,2
\end{tabular}




$\begin{array}{lllll}\text { Salmão } & 64 & 20-22 & 13-15 & 1,3\end{array}$

Fonte: FENNEMA, 1993

A tabela 2 apresenta a composição centesimal média da carne bovina, observa-se que a diferença principal entre os cortes bovinos está na fração lipídica; nos cortes magros, a redução é de até $73,0 \%$. O aumento relativo na concentração de proteínas é conseqüência dessa redução. Com relação ao valor energético, observa-se que os cortes magros fornecem uma redução de $41,0 \%$ nas calorias.

Tabela 2: Composição química média de cortes de carne bovina e de carne de aves in natura e respectivos valores energéticos.

\begin{tabular}{lcccc}
\hline \multicolumn{1}{c}{ Corte/Tipo } & $\begin{array}{c}\text { Energia } \\
\text { (kcal) }\end{array}$ & Gordura total (g) & $\begin{array}{c}\text { Gordura } \\
\text { saturada (g) }\end{array}$ & Proteína (g) \\
\hline & \multicolumn{4}{c}{ CARNE BOVINA } \\
\hline ponta de agulha & 226,2 & 12,5 & 5,3 & 26,4 \\
Picanha & 258,9 & 15,1 & 5,7 & 28,9 \\
Picanha sem capa de & 195,9 & 6,8 & 2,3 & 31,6 \\
gordura & & & & \\
Patinho & 185,1 & 6,9 & 2,4 & 28,7 \\
maminha & 288,0 & 17,4 & 6,6 & 30,7 \\
Língua & 207,1 & 15,9 & Nd & 16,0 \\
Lagarto & 175,2 & 5,7 & 2,1 & 29,0 \\
filé mignon & 211,2 & 10,0 & 3,7 & 28,3 \\
coxão mole & 230,7 & 9,6 & 3,4 & 31,6 \\
coxão duro & 220,3 & 9,4 & 3,2 & 25,0 \\
contra filé & 297,8 & 21,2 & 8,5 & 27,4 \\
Alcatra & 283,2 & 18,4 & 7,7 & 30,9 \\
Alcatra sem capa de & 201,9 & 8,0 & 3,1 & \\
gordura & & & & \\
\hline
\end{tabular}

Fonte: Baseado em Philippi, 2001.

Conforme o guia alimentar de bolso do Ministério da Saúde (2005) deve-se fazer pelo menos 3 refeições (café-da-manhã, almoço e jantar) e 2 lanches saudáveis por dia. Não pular as refeições. Incluir diariamente 6 porções do grupo do cereais (arroz, milho, trigo, pães e massas), tubérculos como as batatas e raízes como a mandioca nas refeições. Dar preferência aos grãos integrais e aos alimentos na sua forma mais natural. Comer diariamente pelo menos 3 porções de legumes e verduras como parte das refeições e 3 porções ou mais de frutas nas sobremesas e lanches.

O prato único neste trabalho apresenta-se então como aquele que possuí todos os ingredientes relativos a uma alimentação saudável e geralmente é servido sem acompanhamento ou guarnição.

Dentre as guarnições/acompanhamentos utilizadas em 18 preparações tem-se: 


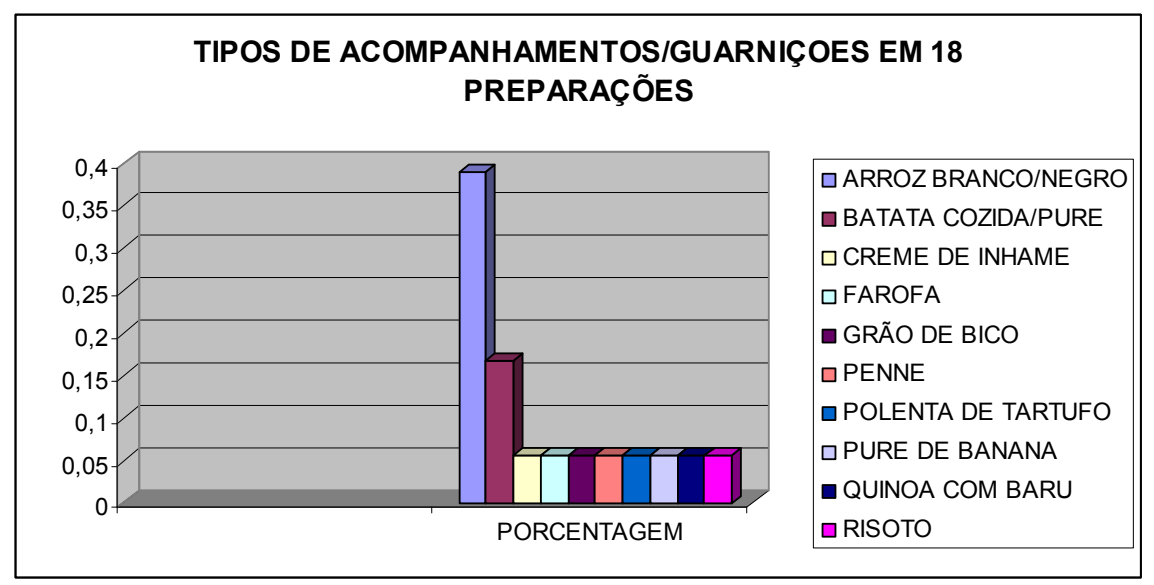

Gráfico 2: Tipos de acompanhamentos/guarnições em 18 preparações

De acordo com Veiros e Proença (2005), têm-se duas classificações para acompanhamentos: 1 - arroz, massas, tubérculos e raízes, 2- hortaliças quentes.

$\mathrm{O}$ arroz é rico em amido e uma ótima fonte de energia. Com isto foi utilizado como um dos principais acompanhamentos pelos restaurantes que participaram do festival, mas que poderiam utilizar maior variedade de hortaliças, aumentando a variedade e ajudando em uma alimentação mais saudável. Justifica-se o uso de arroz como acompanhamento, o fato de culturalmente ser o cereal mais aceito pela população. Dados da Pesquisa de Orçamento Familiar do IBGE (2002-2003) indicam que em todo território nacional, o arroz, é o cereal mais consumido e talvez, consista na principal fonte de carboidratos da população.

As técnicas culinárias privilegiadas no cardápio do festival foram: assados, fervura, grelhados e refogados, como mostra o gráfico abaixo.

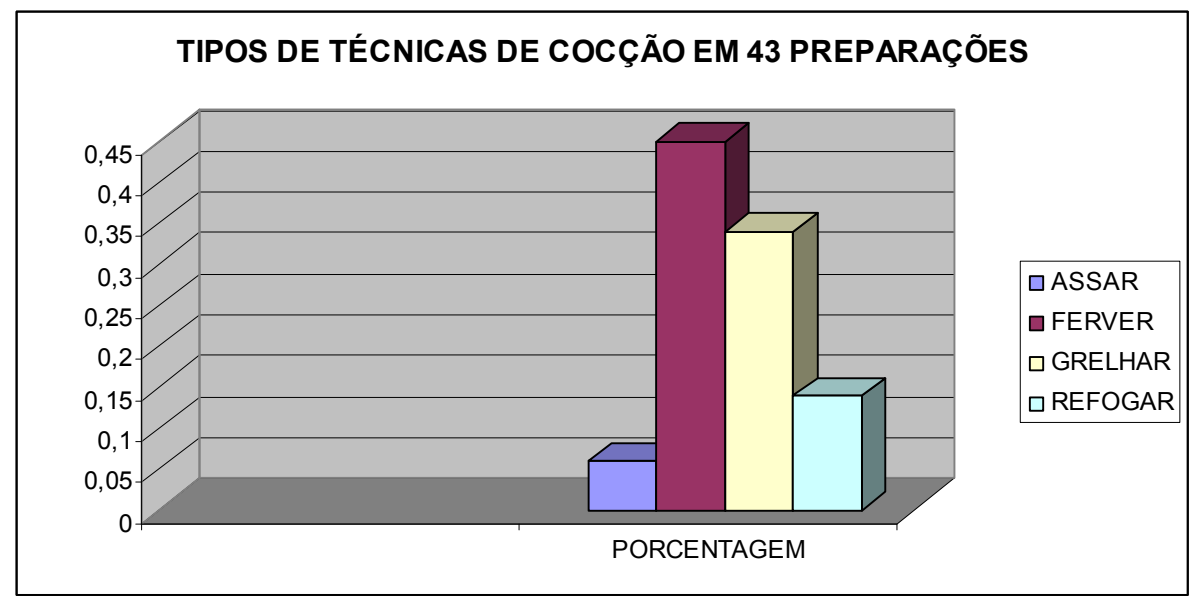

Gráfico 3: Tipos de técnicas de cocção em 43 preparações

Todas as técnicas de cocção citadas não utilizam como meio, obrigatoriamente, a gordura. O assar emprega calor seco, e sua definição segundo Araújo et. al(2007) é fazer o cozimento com a utilização do ar e ou/óleo, usando o forno de convecção ou espetos, que 
podem ser associados ao carvão ou à lenha (churrasco). No caso do grelhar, o alimento é colocado sobre uma chapa ou grelha. E o refogado os alimentos são colocados aos poucos, na panela com pouca gordura, em fogo alto, sendo feita uma rápida fritura.

A fervura se caracteriza pelo calor úmido, que utiliza o meio líquido para o cozimento do alimento em água em ebulição. Todas as técnicas, portanto, beneficiam os preceitos de alimentação saudável, que por sua vez estipulam um consumo máximo de gordura de 15 a $30 \%$ de gordura, em relação ao VET (ARAÚJO et. al., 2007).

Em relação à presença de frutas e hortaliças nas receitas analisadas, identificaram-se os seguintes tipos de hortaliças/frutas em 36 preparações:

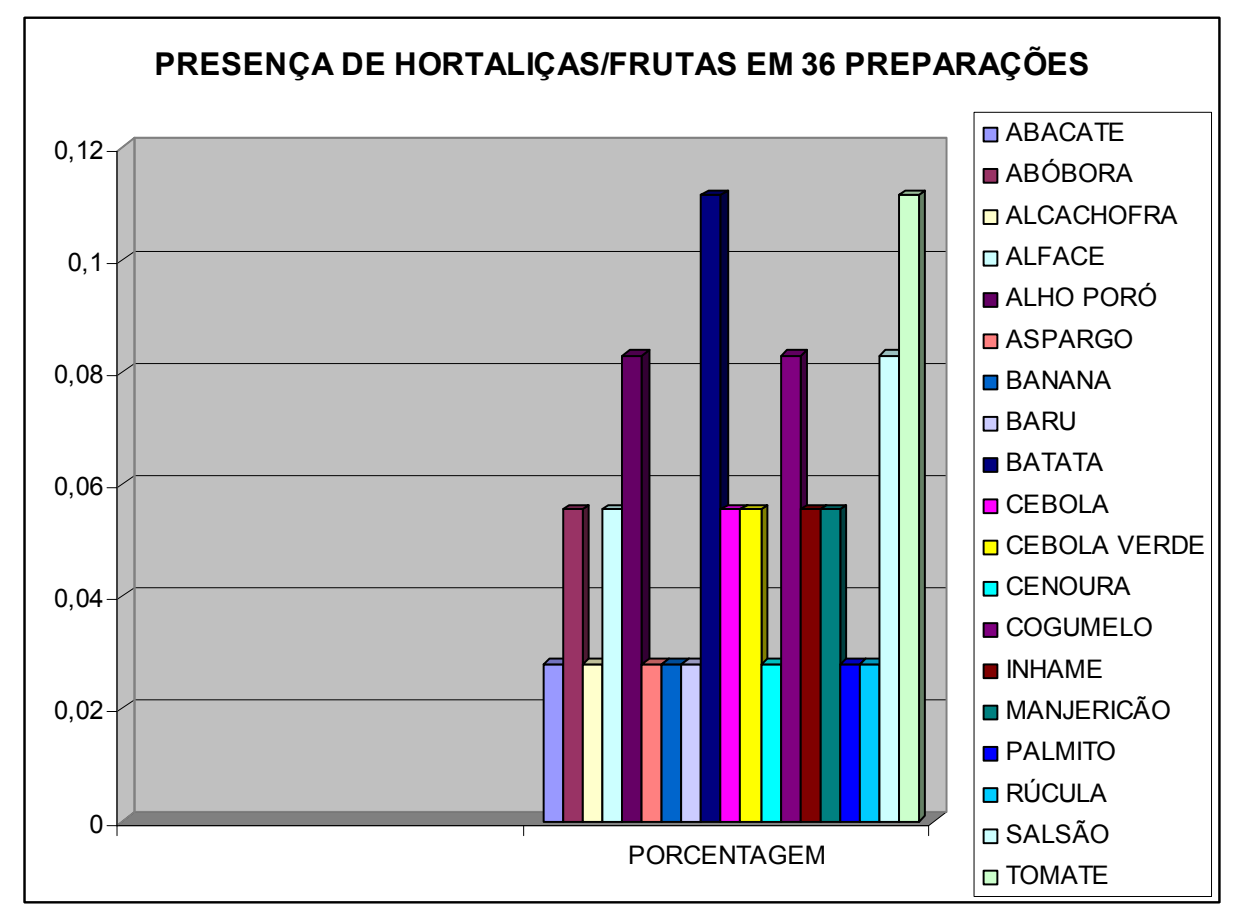

Gráfico 4: Presença de hortaliças/frutas em 36 preparações

A OMS (2002) recomenda o consumo mínimo diário de 400g de frutas e hortaliças, com aumento do consumo de alimentos ricos em fibras, nozes e assemelhados. Com o maior consumo destes alimentos substitui-se por outros de alto valor energético e baixo valor nutritivo, como cereais e grãos processados e açúcar refinado, básicos para o preparo de alimentos industrializados e fast foods. Além de sua possível contribuição no balanço energético, eles podem introduzir nutrientes com efeitos significativos na saúde geral dos indivíduos e, mais especificamente, na prevenção de doenças como obesidade, diabetes tipo 2, doenças cardiovasculares e certos tipos de câncer. Sendo assim, observa-se que a utilização total do grupo de hortaliças e frutas está bem aquém do recomendado.

Confirma-se o fato, ao avaliarem-se as cores presentes nas 43 preparações: 


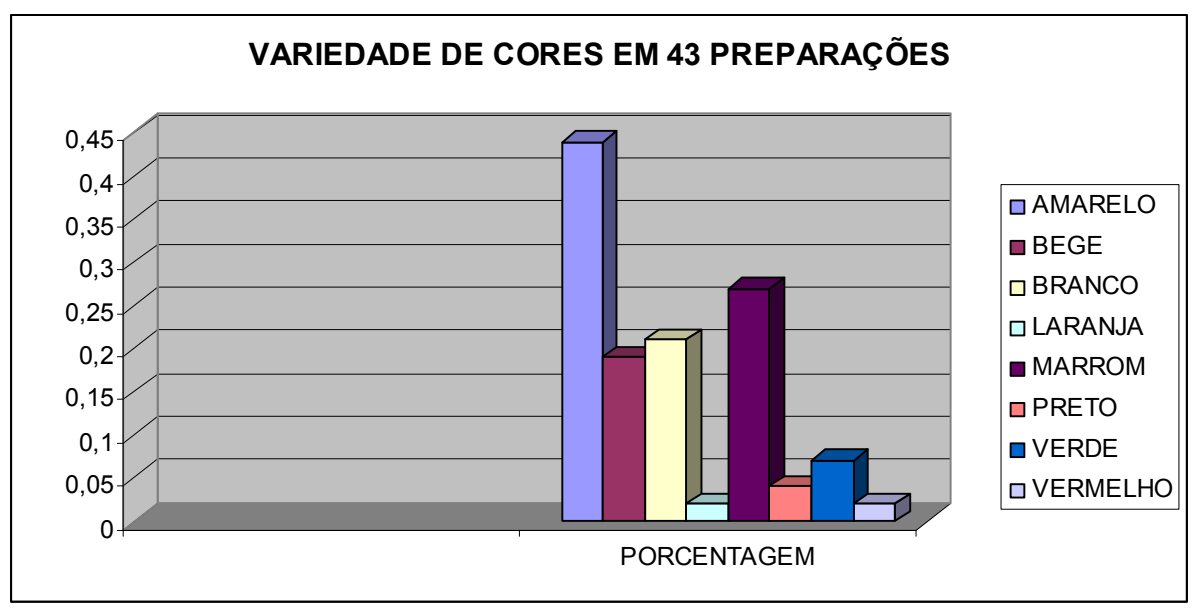

Gráfico 4: Variedade de cores em 43 preparações

As cores das frutas e hortaliças, na maioria dos casos, significam a presença de fitoquímicos - substâncias naturalmente presentes com propriedades funcionais de melhorar o funcionamento do organismo e prevenir doenças. Isto implica na recomendação de um consumo de cores variadas de hortaliças, principalmente as amarelas e as alaranjadas, ricas em betacaroteno - a forma vegetal e precursora da vitamina A, que atua contra a ação dos radicais livres, prevenindo o envelhecimento. Branco/bege rico em minerais, carboidratos e vitamina B6 que auxilia na renovação celular, protege o sistema imunológico e elasticidade dos músculos. Marrom rico em fibras, selênio e vitamina E, que regulam o intestino, melhora a flora intestinal, controla o colesterol e o diabetes. Roxo/preto rico em antocianina, pigmento associado à vitamina $\mathrm{B} 1$, que transforma os nutrientes em energia. Verde, ricos em clorofila, aumenta e energia das células e do organismo e as folhas ainda ricas em ferro e ácido fólico que ajudam no combate a anemia. Vermelho, rico em licopeno geralmente associado à vitamina $\mathrm{C}$ que previne o estresse e funciona como antioxidante no controle dos radicais livres (DSE, 2007). Apresenta-se uma variedade de cores, mas que poderia ser bem mais explorada na diversidade e na quantidade de frutas e hortaliças utilizadas, com isso aumentando a qualidade nutricional das preparações.

Tipos de alimentos com gordura utilizados em 38 preparações: 


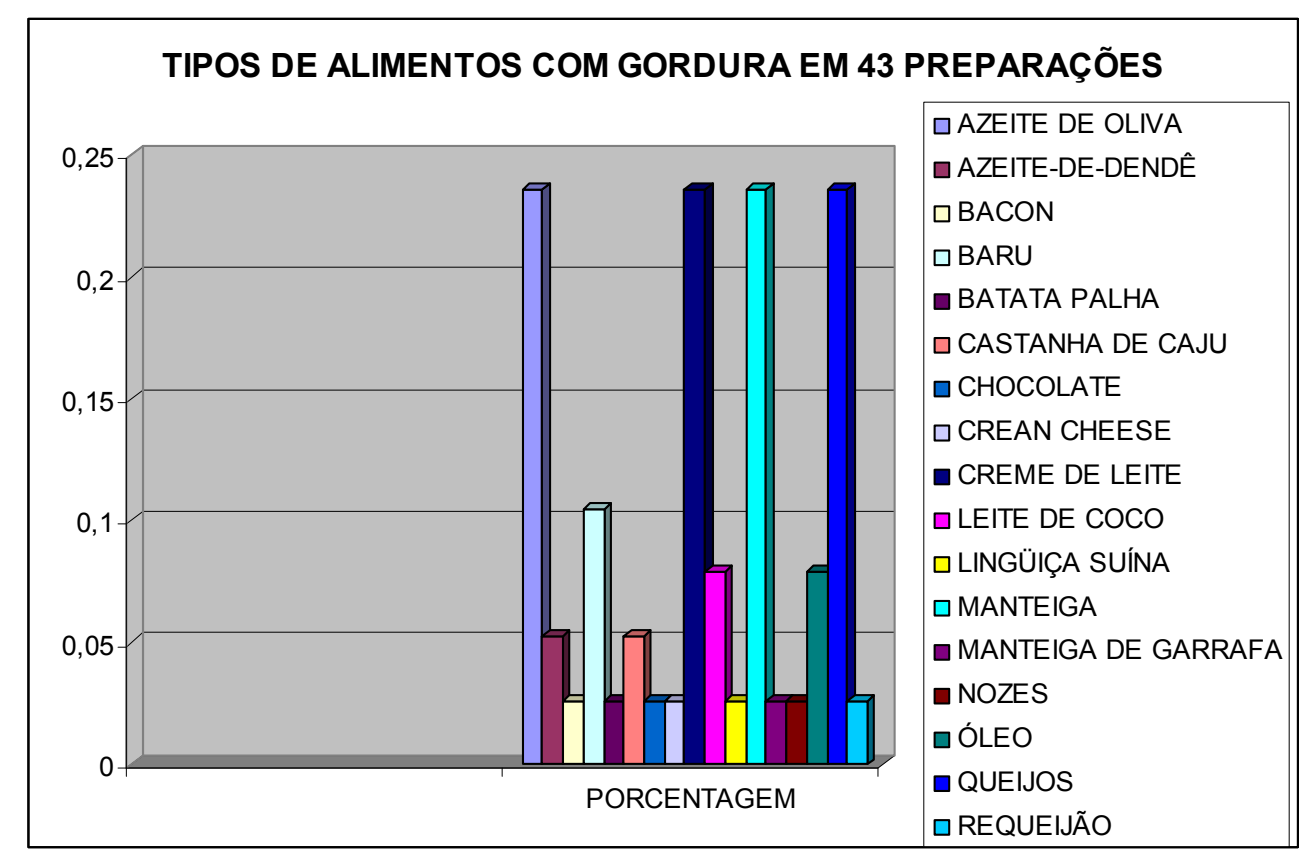

Gráfico 5: Tipos de alimentos com gordura em 38 preparações

Várias preparações apresentam mais um ingrediente gorduroso. No geral as preparações não utilizam tantos ingredientes gordurosos, mas existem algumas que utilizam mais de um na mesma preparação, que acaba por ter seu teor de gordura bem elevado, com isto não atendendo a uma alimentação saudável.

A utilização de gordura em receitas é sensorialmente justificável. A gordura é responsável na aparência por dar cor, brilho, uniformidade na superfície, na textura contribuí para maciez, plasticidade e elasticidade. Muito utilizada em panificação, confeitaria e também como base para temperos e molhos (ARAÚJO et. al., 2007).

\section{CONCLUSÃO}

Diante dos dados avaliados nos resultados e discussão, concluí-se que:

1) As preparações utilizam cortes de carnes com teores baixos de gorduras.

2) $\mathrm{O}$ arroz como sendo um dos principais acompanhamentos, foi o mais utilizado, podendo ter uma maior variedade de hortaliças cozidas para ter uma maior relevância com a alimentação saudável.

3) As técnicas de cocção empregadas atendiam as recomendações, por utilizarem baixo teor de gordura. 
4) A variação de cores como está intimamente ligada com a diversidade de frutas e hortaliças precisa ser bem mais variada, assim aumentado a ingestão de alimentos que possuem nutrientes mais saudáveis.

5) Os alimentos gordurosos precisam ser utilizados em menor escala, pois algumas preparações mostraram o uso de até três ingredientes com gordura, sendo isto prejudicial à saúde, tendo o teor de gordura alto.

6) As preparações apresentadas pelo Festival Gastronômico em termos gerais apresentam preocupações com excessos de gordura, quando se observa as técnicas utilizadas. Contudo, o estimulo ao aumento do uso de frutas e hortaliças, deve ser considerado. São bem balanceadas, tendo algumas que poderiam ser revistas, para terem valores nutricionais melhorados.

7) Os responsáveis pelas preparações devem ter mais atenção com a saúde de seus comensais na hora de executarem suas invenções gastronômicas, sempre tendo em vista uma preparação equilibrada nutricionalmente.

8) Vê-se a necessidade de se fazer um trabalho entre nutricionistas, gastrônomos, chefes e donos dos estabelecimentos, para se ter preparações mais saudáveis tanto nos restaurantes, como nos festivais gastronômicos. 


\section{REFERÊNCIAS BIBLIOGRÁFICAS}

FESTIVAL GASTRONÔMICO DE BRASÍLIA: Segredo dos Chefes, 4. Brasília: SENAC, 2007.

ALLEN, Johnny; O'TOOLE, Willian; MCDONNEL, Ian; HARRIS, Robert. Organização e gestão de eventos. Rio de Janeiro: Campos, 2003.

ARAÚJO, Wilma M.C.; MONTEBELLO, Nancy de Pilla; BOTELHO, Raquel B.A.; BORGO, Luiz Antonio. Alquimia dos alimentos. Brasília, SENAC, 2007.

CAMPOS, Luis Claudio de A.M.; WYSE, Nely; ARAUJO, Maria Luiza M. da S. Eventos: oportunidade de novos negócios. Rio de Janeiro: SENAC, 2000.

FERNANDEZ-ARMESTO, Felipe. Comida: uma história. Rio de Janeiro: Record, 2004.

FRANCO, Ariovaldo. De Caçador a Gourmet - Uma História da Gastronomia. São Paulo: SENAC, 2001.

FREYRE, Gilberto. Açúcar. São Paulo: Cia. das Letras. 2002.

GARCIA, R.W.D. Reflexos da globalização na cultura alimentar: considerações sobre as mudanças na alimentação urbana. Revista Nutrição, Campinas, out./dez., 2003.

GREGSON, Paul William. Festival Gastronômico. São Paulo: Minha Editora, 2005.

MATIAS, Marlene. Organização de eventos: procedimentos e técnicas. Barueri: Manole, 2001.

MAZZINI, I. A alimentação e a medicina no mundo antigo. São Paulo: Estação da Liberdade, 1998.

MEIRELLES, Gilda Fleury. Tudo sobre eventos. O que você precisa saber para criar, organizar e gerenciar eventos que promovem sua empresa e seus produtos. São Paulo: STS, 1999. 
POULAIN, Jean-Pierre. Sociologias da alimentação: os comedores e o espaço social alimentar. Tradução de Rossana P.C. Proença, Carmen S. Rial e Jaimir Conte. Florianópolis: UFSC, 2004.

PROENÇA, Rossana P. da Costa; SOUSA, Anete de Araújo; VEIROS, Marcela Boro; HERING, Bethania. Qualidade nutricional e sensorial na produção de refeições. Florianópolis: UFSC, 2005.

SAVARIN, Brillat. A Fisiologia do gosto. Tradução Paulo Neves. São Paulo: Companhia das Letras, 1999.

SCHLUTER, Regina G. Gastronomia e turismo. São Paulo: Aleph, 2003.

\section{Sites da Internet}

GONÇALVES, Adriana C.; CATTINNE, Érica G. Tipologia dos Eventos. Disponível em $<$ http://www.sinprorp.org.br/Clipping/2003/331.htm>, acesso em 21 de fev. 2008.

BRUIN, Paulo Celso. Planejamento e organização de eventos. Disponível em $<$ http://www.secretariando.com.br/eventos/even-05.htm>, acesso em 21 de fev.2008

Eventos. Disponível em: <http://www.quetalviajar.com/eventos/tipos-de-eventos.htm>, acesso em 21 de fev. 2008.

Ministério da Saúde. Disponível em:

$<$ http://bvsms.saude.gov.br/bvs/publicacoes/glossario_alimenta.pdf $>$, acesso em 07 de jul. 2008 .

Ministério da Saúde. Normas e Manuais Técnicos. Disponível em:

$<$ http://bvsms.saude.gov.br/bvs/publicacoes/glossariotemático alimentação e nutrição.pdf>, acesso em 07 de jul. 2008.

SICHIERI, Rosely et al . Recomendações de alimentação e nutrição saudável para a população brasileira. Arq. bras Endocrinol. Metab., São Paulo, v. 44, n. 3, 2000 . Disponível em: <http://www.scielo.br/scielo>. Acesso em: 07 Jul 2008.

ABRASEL. Disponível em: <http://www.abrasel.com.br>. Acesso em: 30 jun. 2008. 
EMBRATUR. Disponível em: <www.embratur.gov.br>. Acesso em: 07 jul. 2008.

COPACABANA RUNNERS, arroz. Disponível em:

$<$ http://www.copacabanarunners.net/arroz-feijao.html>. Acesso em: 19 jul. 2008. 


\section{APENDICE I}

Restaurante Babel

\begin{tabular}{|c|c|}
\hline \multicolumn{2}{|c|}{ Ficha Técnica de Preparo } \\
\hline $\begin{array}{l}\text { Tipo de Produto (Grupo): prato feito, } \\
\text { refeição }\end{array}$ & $\begin{array}{l}\text { Item: Crusty - escalopes de filé mignon } \\
\text { com risoto }\end{array}$ \\
\hline Porção/ Rendimento: uma pessoa & \multirow[b]{2}{*}{ Modc } \\
\hline Ingredientes: & \\
\hline $\begin{array}{l}\text { Risoto } \\
-25 \text { g de manteiga sem sal }\end{array}$ & \multirow{19}{*}{$\begin{array}{l}\text { - Risoto: dissolva o açafrão no caldo de } \\
\text { legumes. Derreta rapidamente a manteiga } \\
\text { numa frigideira e refogue rapidamente a } \\
\text { cebola. Junte o arroz e, em seguida o vinho } \\
\text { branco. Assim que secar passe a regar com } \\
\text { o caldo de açafrão aos poucos, até o arroz } \\
\text { "al dente”. Junte o tomate, acerte o sal, e } \\
\text { cubra com a castanha de baru. } \\
\text { - Escalope: bata o pão no processador e } \\
\text { misture manualmente à cebola e as ervas } \\
\text { frescas picadas. Tempere os escalopes com } \\
\text { sal e a pimenta moída na hora. Grelhe } \\
\text { rapidamente apenas o suficiente para selar } \\
\text { as superfícies. Retire do fogo e unte as } \\
\text { faces de cada escalope com um pouco de } \\
\text { mostarda. Cubra com a farofa de ervas e } \\
\text { leve ao forno a } 200 \text { graus por } 5 \text { minutos. }\end{array}$} \\
\hline - 1 colher de sopa de cebola picada & \\
\hline - 80g de arroz arbóreo & \\
\hline - $50 \mathrm{ml}$ de vinho branco seco & \\
\hline - $500 \mathrm{ml}$ de caldo de legumes & \\
\hline - 1 colher de chá de açafrão-da-terra & \\
\hline - 1 colher de sopa de tomate concassé & \\
\hline $\begin{array}{l}\text { - } 2 \text { colheres de sopa de castanha de baru } \\
\text { torrada }\end{array}$ & \\
\hline Escalope com crosta & \\
\hline - 1 fatia de pão de forma & \\
\hline - 1 colher de sopa de parmesão ralado & \\
\hline - 1 colher de sopa de manjericão ralado & \\
\hline - 1 colher de sopa de salsinha picada & \\
\hline - 1 colher de sopa de hortelã picada & \\
\hline$-1 / 2$ colher de sopa de cebola picada & \\
\hline - 3 escalopes de filé mignon & \\
\hline - 1 colher de chá de mostarda amarela & \\
\hline - sal a gosto & \\
\hline - pimenta do reino a gosto & \\
\hline
\end{tabular}


Restaurante Azulejaria Bar

\begin{tabular}{|c|c|}
\hline \multicolumn{2}{|c|}{ Ficha Técnica de Preparo } \\
\hline Tipo de Produto (Grupo): prato feito & Item: Steak Café poivre \\
\hline \multicolumn{2}{|l|}{ Porção/ Rendimento: uma pessoa } \\
\hline Ingredientes: & Modo de Preparo: \\
\hline - 200g de filé mignon & \multirow{11}{*}{$\begin{array}{l}\text { - Moa o café e a pimenta. Tempere o filé } \\
\text { mignon com sal, pimenta e café. Sele o } \\
\text { filé em uma frigideira, reservar em } \\
\text { refratário para finalizar no forno. Utilizar a } \\
\text { mesma frigideira e jogar o brandy (deixar } \\
\text { reduzir). Acrescente o caldo de carne e } \\
\text { deixe reduzir por } 5 \text { minutos. Acrescente o } \\
\text { creme de leite e deixe reduzir por mais } 3 \\
\text { minutos. Corte as batatas no sentido } \\
\text { longitudinal (com casca), cozinhe em água } \\
\text { abundante por } 20 \text { minutos. Seque a batata } \\
\text { em forno a } 280 \text { graus, por } 20 \text { minutos, } \\
\text { com um fio de azeite. } \\
\text { Coloque a carne e por cima jogue o molho. } \\
\text { Coloque as batatas ao lado e regue com } \\
\text { um fio de azeite de trutas brancas. }\end{array}$} \\
\hline - 20g de pimenta do reino preta & \\
\hline - 20g de grãos de café de boa qualidade & \\
\hline - $20 \mathrm{ml} \mathrm{de} \mathrm{creme} \mathrm{de} \mathrm{leite} \mathrm{fresco}$ & \\
\hline - $50 \mathrm{ml}$ de brandy & \\
\hline - $100 \mathrm{ml}$ de caldo de carne & \\
\hline - 200g de batata & \\
\hline - 20g de manteiga sem sal & \\
\hline - azeite com trufas brancas & \\
\hline - sal a gosto & \\
\hline & \\
\hline
\end{tabular}


Restaurante e Bar do Calaf

\begin{tabular}{|c|c|}
\hline \multicolumn{2}{|c|}{ Ficha Técnica de Preparo } \\
\hline Tipo de Produto (Grupo): prato feito & Item: Costelletes de Corder a l'all-i-oil \\
\hline \multicolumn{2}{|l|}{ Porção/ Rendimento: uma pessoa } \\
\hline Ingredientes: & Modo de Preparo: \\
\hline - 4 bistecas de cordeiro mamão & \multirow{9}{*}{$\begin{array}{l}\text { - Corte as bistecas com um dedo de } \\
\text { espessura, tempere com sal e grelhe. } \\
\text { Tempere as mini-batatas e as cebolas com } \\
\text { um pouco de alecrim e asse-as a } 200 \text { graus } \\
\text { por } 20 \text { minutos ou até murcharem um } \\
\text { pouco. O all-i-oli é feito no liquidificador } \\
\text { com um ovo, mostarda, dois dentes de } \\
\text { alho e azeite de oliva. } \\
\text { Monte as bistecas com as batatas e as } \\
\text { cebolas, distribua o all-i-oil com a porção } \\
\text { de arroz. }\end{array}$} \\
\hline - $100 \mathrm{~g}$ de mini-batatas & \\
\hline - 100g de mini-cebolas & \\
\hline-1 ovo & \\
\hline - 2 dentes de alho & \\
\hline - 1 colher de sopa de mostarda & \\
\hline - $300 \mathrm{ml}$ de azeite de oliva & \\
\hline - 1 porção pequena de arroz & \\
\hline & \\
\hline
\end{tabular}


Restaurante BSB Gril

\begin{tabular}{|c|c|}
\hline \multicolumn{2}{|c|}{ Ficha Técnica de Preparo } \\
\hline $\begin{array}{l}\text { Tipo de Produto (Grupo): refeição, prato } \\
\text { principal }\end{array}$ & $\begin{array}{l}\text { Item: T-Bone e Teen Beef com arroz Biro- } \\
\text { Biro e farofa de ovos }\end{array}$ \\
\hline Porção/ Rendimento: duas pessoas & \\
\hline Ingredientes: & \multirow{16}{*}{$\begin{array}{l}\text { Modo de Preparo: } \\
\text { - T-Bone: polvilhe com sal grosso e leve } \\
\text { para assar na grelha quente, em braseiro } \\
\text { forte por } 10 \text { minutos de cada lado no } \\
\text { máximo e reserve. } \\
\text { - Farofa de ovos: leve ao fogo uma panela } \\
\text { com pouco de óleo e coloque os ovos, vá } \\
\text { mexendo devagar, não deixando ficar com } \\
\text { os pedaços dos ovos muito quebrados, } \\
\text { quando estiverem fritos adicione a farinha } \\
\text { de mandioca. Mexa bem e acrescente a } \\
\text { cebolinha verde e reserve. } \\
\text { - Arroz Biro-biro: prepare o arroz branco e } \\
\text { separe. Leve ao fogo uma panela com óleo } \\
\text { e adicione a lingüiça, acrescente a } \\
\text { cebolinha verde picada, mexendo de vez } \\
\text { em quando. Quando a lingüiça estiver } \\
\text { frita, adicione os ovos sempre mexendo. } \\
\text { Acrescente o arroz já cozido misture bem } \\
\text { e retire do fogo. Coloque a batata palha } \\
\text { por cima servindo em seguida. } \\
\text { Sirva o T-Bone e os outros em pratos } \\
\text { separados. }\end{array}$} \\
\hline $\begin{array}{l}\text { - 400g de Teen Beef: carne extra-virgem, } \\
\text { melhor sabor e T-Bone: a parte da bisteca } \\
\text { bovina com } 70 \% \text { de contrafilé e } 30 \% \text { de } \\
\text { filé mignon (dois cortes) }\end{array}$ & \\
\hline Arroz Biro-Biro & \\
\hline - 4 xícaras de arroz & \\
\hline - 2 colheres de sopa de azeite e margarina & \\
\hline - 1 maço de cebolinha picada & \\
\hline - 300g de lingüiça suína sem pele picada & \\
\hline-4 ovos & \\
\hline - 200g de batata palha & \\
\hline Farofa de ovos & \\
\hline - óleo & \\
\hline-3 ovos & \\
\hline - $200 \mathrm{~g}$ farinha de mandioca fina & \\
\hline - cebolinha verde picada & \\
\hline - sal a gosto & \\
\hline & \\
\hline
\end{tabular}


Restaurante Café Antiquário

\begin{tabular}{|c|c|}
\hline \multicolumn{2}{|c|}{ Ficha Técnica de Preparo } \\
\hline Tipo de Produto (Grupo): prato feito & $\begin{array}{l}\text { Item: Escondidinho de Camarão com } \\
\text { Creme de Inhame }\end{array}$ \\
\hline Porção/ Rendimento: quatro pessoas & \\
\hline Ingredientes: & Modo de Preparo: \\
\hline - Camarão: & - Camarão: prepare um caldo utilizando 2 \\
\hline - $1 \mathrm{~kg}$ de camarões médios & litros de água, as cascas do camarão, $1 / 2$ \\
\hline - 2 litros de água & cebola, um tomate limpo, duas folhas de \\
\hline - 1 alho poró picado & louro, dois dentes de alho, metade do alho \\
\hline - 1 talo de salsão & poró e $1 / 2$ talo de salsão. Cozinhe tudo em \\
\hline - 1 cebola média ralada & fogo médio por 10 minutos. Coloque o \\
\hline - 3 dentes de alho & camarão de molho com limão, sal e a \\
\hline - 1 tomate limpo & pimenta por 10 minutos. Numa caçarola \\
\hline - 1 limão espremido & frite um dente de alho, depois acrescente \\
\hline - 3 folhas de louro & $1 / 2$ cebola picada, $1 / 2$ alho poro, uma folha \\
\hline - $100 \mathrm{ml}$ de leite de coco & de louro, inhame em cubos. Coloque o \\
\hline - $250 \mathrm{ml}$ de creme de leite fresco & caldo e deixe cozinhar por 3 minutos. \\
\hline - $50 \mathrm{~g}$ de queijo gruyère fundido & Acrescente o camarão em cubos junto com \\
\hline - $200 \mathrm{~g}$ de inhame cortado em cubos & o leite de coco e o queijo Gruyère e \\
\hline - $50 \mathrm{ml}$ de azeite extra-virgem & cozinhe até ficar bem cremoso. \\
\hline - pimenta-do-reino e sal a gosto & - Creme de inhame: cozınhe o inhame ate \\
\hline - creme de inhame: & f1car bem macio. Passe numa peneira ou \\
\hline - $1 \mathrm{~kg}$ de inhame limpo e sem casca & no espremedor de batatas e leve ao togo. \\
\hline - $200 \mathrm{ml}$ de creme de leite fresco & Coloque o creme de leite, manteiga, sal e a \\
\hline - $50 \mathrm{~g}$ de manteiga sem sal & noz moscada a gosto. \\
\hline - sal e noz moscada a gosto & 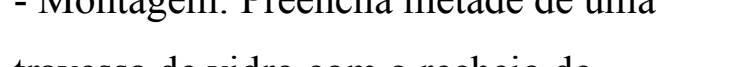 \\
\hline - para finalizar: & camarão Cuhra com creme de inhame \\
\hline - $100 \mathrm{~g}$ de coco ralado em flocos & Salniaue o queiio ralado e finalize com o \\
\hline - 100g de queijo Grana Padano ralado & flocos de coco ralado e gratine. \\
\hline
\end{tabular}


Café Cassis

\begin{tabular}{|c|c|}
\hline \multicolumn{2}{|c|}{ Ficha Técnica de Preparo } \\
\hline Tipo de Produto (Grupo): entrada/lanche & Item: Taco Wrap Combo \\
\hline \multicolumn{2}{|l|}{ Porção/ Rendimento: duas pessoas } \\
\hline Ingredientes: & Modo de Preparo: \\
\hline - 1 colher de sopa de azeite de oliva & \multirow{16}{*}{$\begin{array}{l}\text { - Esquente o azeite em fogo médio, } \\
\text { acrescente cebola, refogue e acrescente o } \\
\text { alho quando a cebola estiver transparente. } \\
\text { Refogue durante } 1 \text { minuto, aumente o fogo } \\
\text { e adicione a carne, o tomate e tempere a } \\
\text { gosto. Acrescente o molho de tomate e a } \\
\text { água e cozinhar em fogo brando até quase } \\
\text { secar. } \\
\text { No pão folha, coloque } 2 \text { fatias de queijo } \\
\text { em cada, no centro dele com } \\
\text { aproximadamente } 2 \text { dedos de distância } \\
\text { para a borda. } \\
\text { Divida a carne, as tortilhas, o abacate e } \\
\text { alface em cada pão folha e enrole-os. Corte } \\
\text { ao meio e sirva. }\end{array}$} \\
\hline - 1 colher de sopa de cebola picada & \\
\hline - 2 dentes de alho picados & \\
\hline - 250 g de carne moída & \\
\hline - 1 tomate sem semente picado & \\
\hline - 3 colheres de sopa de molho de tomate & \\
\hline - 100 ml de água & \\
\hline - sal, pimenta, pó de chilli a gosto & \\
\hline - pitada de cominho e coentro moídos & \\
\hline - salsinha picada & \\
\hline - 4 fatias de queijo tipo cheddar & \\
\hline - alface picada & \\
\hline - 1 xícara de chá de tortilhas esfareladas & \\
\hline - 2 colheres de sopa & \\
\hline - $1 / 4$ de abacate em cubos pequenos & \\
\hline - 2 pães folhas pronto & \\
\hline
\end{tabular}


Cést si bom Crêperie

\begin{tabular}{|c|c|}
\hline \multicolumn{2}{|c|}{ Ficha Técnica de Preparo } \\
\hline Tipo de Produto (Grupo): entrada, lanche & $\begin{array}{l}\text { Item: Marle Dietrich } \\
\text { Crepe recheado }\end{array}$ \\
\hline Porção/ Rendimento: 15 crepes & \\
\hline Ingredientes: & Modo de Preparo: \\
\hline - massa: & - Bata no liquidificador o leite, os ovos, \\
\hline - 1 litro de leite & açúcar e sal. Acrescente a farinha de trigo \\
\hline-3 ovos & aos poucos. Depois de homogeneizado \\
\hline - 75 g de manteiga derretida & adicione a cerveja e por último a manteiga \\
\hline - 1 colher de chá de açúcar & derretida. Deixe descansar. \\
\hline - $750 \mathrm{~g}$ de farinha de trigo & Abra a massa em chapa própria para \\
\hline - 1 xícara de café de cerveja & crepes ou em frigideira. \\
\hline - recheio: & Tempere e grelhe o salmão em frigideira \\
\hline - $1 \mathrm{~kg}$ de salmão grelhado desfiado & com manteiga. Desfie e reserve. $\mathrm{Na}$ \\
\hline - 10 endívias picadas & mesma frigideira refogue a endívia \\
\hline - $300 \mathrm{ml} \mathrm{de} \mathrm{cerveja}$ & deglaçando-a com a cerveja. Reserve. \\
\hline - sal e pimenta a gosto & Junte o salmão desfiado com a endívia e \\
\hline$-1 / 2 \mathrm{~kg}$ de requeijão cremoso & $\begin{array}{l}\text { misture ao requeijão cremoso. Recheie o } \\
\text { crepe pela metade e volte com ele a } \\
\text { frigideira para dourar os lados da massa e } \\
\text { sirva dobrado-o novamente. }\end{array}$ \\
\hline
\end{tabular}


Confeitaria Francesa

\begin{tabular}{|c|c|}
\hline \multicolumn{2}{|c|}{ Ficha Técnica de Preparo } \\
\hline Tipo de Produto (Grupo): sobremesa & $\begin{array}{l}\text { Item: Amour-Amour } \\
\text { Merengue recheado com chocolate }\end{array}$ \\
\hline Porção/ Rendimento: 10 doces & \\
\hline Ingredientes: & Modo de Preparo: \\
\hline - $250 \mathrm{~g}$ de clara de ovos & - Misture as $250 \mathrm{~g}$ de claras de ovos com o \\
\hline - 750 d de açúcar & açúcar e leve ao fogo brando até dissolver \\
\hline - $250 \mathrm{~g}$ de chocolate meio-amargo & o açúcar. Depois de dissolvido coloque na \\
\hline - uma lata de creme de leite & batedeira até adquirir uma consistência de \\
\hline - 3 claras de ovos & "picos". Coloque o creme (merengue) em \\
\hline & $\begin{array}{l}\text { um bico perlé, unte a assadeira e farinhe } \\
\text { (ou coloque papel impermeável). Faça } \\
\text { desenhos em forma de discos (começando } \\
\text { do interior para o exterior do círculo } \\
\text { desenhado), com +-20 cm de diâmetro. } \\
\text { Leve ao forno aquecido em torno de } 50 \\
\text { graus, por aproximadamente } 40 \text { a } 50 \\
\text { minutos (até o suspiro soltar da assadeira). } \\
\text { Para fazer a mousse, derreta em banho- } \\
\text { maria o chocolate e reserve. Bata as três } \\
\text { claras em neve, até a mesma adquirir uma } \\
\text { consistência de "picos". Acrescente } \\
\text { lentamente ao chocolate derretido e mexa } \\
\text { bem devagar as claras em neve. Por último } \\
\text { acrescente o creme de leite sem soro. Leve } \\
\text { a mousse à geladeira e deixe gelar por pelo } \\
\text { menos duas horas. Coloque o disco de } \\
\text { merengue em um prato, acrescente duas } \\
\text { colheres da mousse de chocolate e coloque } \\
\text { outro disco de merengue acima. Coloque } \\
\text { chantily e enfeite com morangos a gosto. }\end{array}$ \\
\hline
\end{tabular}


Restaurante Confraria do Camarão

\begin{tabular}{|c|c|}
\hline \multicolumn{2}{|c|}{ Ficha Técnica de Preparo } \\
\hline $\begin{array}{l}\text { Tipo de Produto (Grupo): prato feito, } \\
\text { refeição }\end{array}$ & Item: Espaguete Confraria \\
\hline Porção/ Rendimento: duas pessoas & \\
\hline Ingredientes: & Modo de Preparo: \\
\hline$-30 \mathrm{~g}$ de funghi seco & - Coloque o funghi de molho em um \\
\hline - $45 \mathrm{ml}$ de azeite extra-virgem & recipiente com $250 \mathrm{ml}$ de água morna por \\
\hline - $60 \mathrm{~g}$ de cebola picada & pelo menos 20 minutos. Retire-os, \\
\hline - sal e pimenta-do-reino a gosto & esprema o excesso de água no recipiente, \\
\hline - 150 g de camarões médios, limpos & então os enxágüe sob água corrente e \\
\hline - $60 \mathrm{ml} \mathrm{de} \mathrm{creme} \mathrm{de} \mathrm{leite} \mathrm{sem} \mathrm{soro}$ & pique-os ligeiramente. Filtre a água em \\
\hline - 300 g de espaguete cozido al dente & que ficaram de molho em toalha ou filtro \\
\hline & $\begin{array}{l}\text { de papel e reserve. Depois coloque o azeite } \\
\text { e a cebola em uma panela grande sobre } \\
\text { fogo médio e cozinhe até a cebola } \\
\text { amolecer e ficar bem dourada. Em } \\
\text { seguida, adicione o funghi reconstituído } \\
\text { em água filtrada, aumente o fogo e } \\
\text { cozinhe, mexendo, até quase toda a água } \\
\text { ter evaporado. Adicione sal e a pimenta. } \\
\text { Junte os camarões, adicione o creme de } \\
\text { leite e cozinhe, mexendo todo o tempo, até } \\
\text { reduzir à metade. Retire a panela do fogo. } \\
\text { Junte o espaguete cozido e quente ao } \\
\text { molho e sirva a seguir. }\end{array}$ \\
\hline
\end{tabular}


Crepe au Chocolat

\begin{tabular}{|l|l|}
\hline \multicolumn{2}{|c|}{ Ficha Técnica de Preparo } \\
\hline Tipo de Produto (Grupo): entrada, lanche & Item: Alcachofras AL Pesto \\
\hline Porção/ Rendimento: uma pessoa & \multicolumn{1}{|l|}{ Modo de Preparo: } \\
\hline Ingredientes: & $\begin{array}{l}\text { - massa: bata no liquidificador os } \\
\text { ingredientes e deixe descasar por } 20\end{array}$ \\
\hline -130 g de mussarela de búfala ralada \\
- 50 g de queijo grana padano ralado
\end{tabular}


Restaurante Don Pepe Enogastronomia

\begin{tabular}{|c|c|}
\hline \multicolumn{2}{|c|}{ Ficha Técnica de Preparo } \\
\hline Tipo de Produto (Grupo): prato feito & $\begin{array}{l}\text { Item: Lombinho de Cordeiro com Polenta } \\
\text { de Tartufo }\end{array}$ \\
\hline \multicolumn{2}{|l|}{ Porção/ Rendimento: uma pessoa } \\
\hline Ingredientes: & Modo de Preparo: \\
\hline - $200 \mathrm{~g}$ de cordeiro & \multirow{13}{*}{$\begin{array}{l}\text { - cordeiro: deixe o cordeiro em uma } \\
\text { panela marinado com o vinho tinto, salsão, } \\
\text { alho poro, cenoura, alecrim, tomilho, alho } \\
\text { com casca, pimenta e sal a gosto. Deixe } \\
\text { descansado por } 6 \text { horas e depois leve ao } \\
\text { forno por } 30 \text { minutos. } \\
\text { - polenta: coloque em uma panela caldo de } \\
\text { legumes, acrescente a polenta e leve ao } \\
\text { forno brando. Deixe cozinhar até ficar } \\
\text { encorpado e em seguida acrescente o } \\
\text { queijo com o tartufo. } \\
\text { Monte em um prato a polenta, acrescente } \\
\text { sobre ela o cordeiro, regue com um pouco } \\
\text { de molho da assadeira e sirva. }\end{array}$} \\
\hline - 1 galho de alecrim & \\
\hline - 1 galho de tomilho & \\
\hline - $100 \mathrm{ml}$ de vinho tinto seco & \\
\hline - 1 talo de salsão & \\
\hline - 1 talo de alho poro & \\
\hline - sal e pimenta a gosto & \\
\hline - 2 dentes de alho com casca & \\
\hline - 2 cenouras & \\
\hline$-60 \mathrm{~g}$ de polenta & \\
\hline - $15 \mathrm{~g}$ de queijo grana padano & \\
\hline - tartufo & \\
\hline & \\
\hline
\end{tabular}


Restaurante Dudu Camargo

\begin{tabular}{|c|c|}
\hline \multicolumn{2}{|c|}{ Ficha Técnica de Preparo } \\
\hline Tipo de Produto (Grupo): prato feito & Item: Robalo do Centro-Oeste \\
\hline \multicolumn{2}{|l|}{ Porção/ Rendimento: uma pessoa } \\
\hline Ingredientes: & Modo de Preparo: \\
\hline - 220 g de filé de robalo & \multirow{14}{*}{$\begin{array}{l}\text { - Tempere o peixe com o suco de limão, } \\
\text { sal e pimenta. Grelhe com azeite de oliva e } \\
\text { reserve. Misture bem todos outros } \\
\text { ingredientes e cubra o peixe já grelhado. } \\
\text { Leve ao forno pré-aquecido para dourar. } \\
\text { Refogue a cebola na manteiga, acrescente } \\
\text { o caju passa e o creme de leite. Deixe } \\
\text { ferver e junte o arroz. Mexa bem até ficar } \\
\text { cremoso. } \\
\text { - Montagem: sirva o peixe no prato } \\
\text { guarnecido pelo arroz com caju passa e } \\
\text { decore com azeite aromatizado de aniz } \\
\text { estrelado e alho. }\end{array}$} \\
\hline - suco de limão & \\
\hline - sal e pimenta a gosto & \\
\hline - $20 \mathrm{~g}$ de baru torrado e moído finamente & \\
\hline - 2 fatias de pão de forma esfarelado & \\
\hline $\begin{array}{l}\text { - ervas frescas picadas (alecrim, tomilho, } \\
\text { manjericão e orégano) }\end{array}$ & \\
\hline - $20 \mathrm{~g}$ de manteiga & \\
\hline - sal a gosto & \\
\hline - Para o arroz: & \\
\hline - 150 g de arroz cozido & \\
\hline - $30 \mathrm{~g}$ de caju passa em tiras & \\
\hline - $50 \mathrm{ml} \mathrm{de} \mathrm{creme} \mathrm{de} \mathrm{leite} \mathrm{fresco}$ & \\
\hline - 1 colher de sobremesa de manteiga & \\
\hline - 1 colher de sopa de cebola picada & \\
\hline
\end{tabular}


Restaurante El Paso texas

\begin{tabular}{|c|c|}
\hline \multicolumn{2}{|c|}{ Ficha Técnica de Preparo } \\
\hline Tipo de Produto (Grupo): entrada, petisco & Item: Tacos El Paso de Camarões \\
\hline \multicolumn{2}{|l|}{ Porção/ Rendimento: duas pessoas } \\
\hline Ingredientes: & Modo de Preparo: \\
\hline - tortilhas: & \multirow{19}{*}{$\begin{array}{l}\text { - Tortilhas: misture bem todos os } \\
\text { ingredientes e abra a massa com um rolo } \\
\text { para ficar bem fina. Corte em círculos pré- } \\
\text { asse em uma frigideira antiaderente. Após } \\
\text { assada, frite as tortilhas em óleo bem } \\
\text { quente para que fiquem em forma de } \\
\text { "concha" semi-aberta. } \\
\text { - Guacamole: misture todos os } \\
\text { ingredientes. } \\
\text { - Sour Cream: bata todos os ingredientes } \\
\text { em uma batedeira. } \\
\text { - Montagem: Nas tortilhas coloque } \\
\text { primeiramente o queijo, em seguida os } \\
\text { camarões grelhados. Cubra com alface e o } \\
\text { tomate picados, coloque sobre eles o } \\
\text { guacamole e por cima de tudo o sour } \\
\text { cream. }\end{array}$} \\
\hline - 500 g de fécula de milho & \\
\hline - $250 \mathrm{ml}$ de água quente & \\
\hline - $50 \mathrm{ml}$ de gordura vegetal hidrogenada & \\
\hline - recheio: & \\
\hline - 600 g de camarão rosa descascado & \\
\hline - 2 tomates em cubos & \\
\hline $\begin{array}{l}\text { - } 4 \text { folhas de alface americana cortadas } \\
\text { finamente }\end{array}$ & \\
\hline - $200 \mathrm{~g}$ de queijo minas semicurado ralado & \\
\hline - sal e alho a gosto & \\
\hline - guacamole: & \\
\hline - 2 abacates amassados & \\
\hline - 1 suco de limão & \\
\hline$-1 / 2$ cebola ralada finamente & \\
\hline - sal e pimenta branca a gosto & \\
\hline - sour cream: & \\
\hline - $250 \mathrm{~g}$ de creme de leite fresco & \\
\hline - 1/2 limão espremido & \\
\hline - sal e pimenta branca a gosto & \\
\hline
\end{tabular}


Restaurante Esquina Mineira

\begin{tabular}{|c|c|}
\hline \multicolumn{2}{|c|}{ Ficha Técnica de Preparo } \\
\hline $\begin{array}{l}\text { Tipo de Produto (Grupo): prato feito, prato } \\
\text { principal }\end{array}$ & $\begin{array}{l}\text { Item: Feijoada de frutos do mar servida à } \\
\text { moda mineira }\end{array}$ \\
\hline Porção/ Rendimento: quatro pessoas & \multirow[b]{2}{*}{ Modo de Preparo: } \\
\hline Ingredientes: & \\
\hline $\begin{array}{l}\text { - } 1 \text { litro de caldo de peixe ( } 92 \text { tabletes de } \\
\text { caldo de peixe ou camarão dissolvido em } 1 \\
\text { litro de água) }\end{array}$ & \multirow{16}{*}{$\begin{array}{l}\text { - Em uma panela, coloque o caldo de peixe } \\
\text { com as favas e deixe cozinhar por } 10 \\
\text { minutos. Em outra panela, com o azeite- } \\
\text { de-dendê, refogue a cebola, o alho, a } \\
\text { pimenta-de-cheiro, o pimentão e o tomate } \\
\text { por } 5 \text { minutos, em fogo médio. Junte o } \\
\text { refogado às favas e ao caldo de peixe, } \\
\text { acrescentando o leite de coco e o peixe } \\
\text { cortado em cubos. Deixe em fogo médio } \\
\text { por } 10 \text { minutos. Coloque o polvo e a lula } \\
\text { já cozidos, o camarão e o vôngole e } \\
\text { cozinhe por mais } 3 \text { minutos. Acerte o sal. } \\
\text { Salpique salsinha a gosto. Sirva com arroz } \\
\text { branco. }\end{array}$} \\
\hline - $500 \mathrm{~g}$ de favas cozidas & \\
\hline - 1/4 de xícara de chá de azeite-de-dendê & \\
\hline - 1 cebola picada & \\
\hline - 2 dentes de alho picados & \\
\hline - 1 pimenta-de-cheiro cortada em rodelas & \\
\hline $\begin{array}{l}\text { - } 1 / 2 \text { pimentão vermelho cortado em } \\
\text { cubinhos }\end{array}$ & \\
\hline $\begin{array}{l}\text { - } 1 \text { tomate sem pele e sem semente cortado } \\
\text { em pedaços pequenos }\end{array}$ & \\
\hline - $200 \mathrm{ml}$ de leite de coco & \\
\hline $\begin{array}{l}\text { - 500g de namorado ou garoupa cortada } \\
\text { em cubos }\end{array}$ & \\
\hline $\begin{array}{l}\text { - } 200 \mathrm{~g} \text { de polvo cozido em pedaços } \\
\text { pequenos }\end{array}$ & \\
\hline - 200 g de lula cozida cortada em anéis & \\
\hline - 200 g de camarão médio & \\
\hline - $150 \mathrm{~g}$ de vôngole sem a casca e limpo & \\
\hline - sal a gosto & \\
\hline - salsinha a gosto & \\
\hline
\end{tabular}


Restaurante Fred

\begin{tabular}{|c|c|}
\hline \multicolumn{2}{|c|}{ Ficha Técnica de Preparo } \\
\hline $\begin{array}{l}\text { Tipo de Produto (Grupo): prato principal, } \\
\text { prato feito }\end{array}$ & Item: Kassler na cerveja \\
\hline Porção/ Rendimento: quatro pessoas & \multirow[b]{2}{*}{ Modo de Preparo: } \\
\hline Ingredientes: & \\
\hline - 4 kassler (carré suíno defumado) & \multirow{16}{*}{$\begin{array}{l}\text { - Numa frigideira de fundo grosso, derreta } \\
\text { a manteiga e óleo. Refogue o alho, } \\
\text { adicione a cebola, o tomilho e o açúcar } \\
\text { mascavo. Tampe a panela e cozinhe em } \\
\text { fogo médio até a cebola ficar macia. } \\
\text { Destampe a panela, aumente a chama e } \\
\text { refogue até a mistura ficar bem dourada. } \\
\text { Adicione a farinha de trigo e mexa por } 1 \\
\text { minuto. Acrescente o caldo, a cerveja e } \\
\text { uma pitada de sal e pimenta. Deixe } \\
\text { levantar fervura, abaixe o fogo e cozinhe } \\
\text { por } 5 \text { minutos até o molho ficar brilhante e } \\
\text { levemente encorpado. Acerto o sal e } \\
\text { reserve. Grelhe o salsichão previamente } \\
\text { cozido e o kassler em chapa grossa } \\
\text { aquecida e untada com óleo. Não é } \\
\text { necessário cozinhar nem temperar o } \\
\text { kassler, pois já vem pronto para grelhar. } \\
\text { Sirva o molho quente sobre o kassler e a } \\
\text { salsinha, com o salsichão e acompanhado } \\
\text { de purê de batatas. }\end{array}$} \\
\hline - 4 salsichões de Vitela & \\
\hline - 2 colheres de sopa de óleo vegetal & \\
\hline - molho: & \\
\hline - 1 colher de sopa de manteiga sem sal & \\
\hline - 1 colher de sopa de óleo vegetal & \\
\hline - 1 colher de tomilho em flocos & \\
\hline - 4 folhas de sálvia picadas & \\
\hline - $500 \mathrm{~g}$ de cebola fatiadas & \\
\hline - 1 colher de chá de açúcar mascavo & \\
\hline - 2 dentes de alho esmagados & \\
\hline - 1 colher de sopa de farinha de trigo & \\
\hline - $150 \mathrm{ml}$ de caldo de carne & \\
\hline - 1 lata de cerveja & \\
\hline - sal e pimenta-do-reino a gosto & \\
\hline & \\
\hline
\end{tabular}


Restaurante Gazebo

\begin{tabular}{|c|c|}
\hline \multicolumn{2}{|c|}{ Ficha Técnica de Preparo } \\
\hline Tipo de Produto (Grupo): prato feito & Item: Filet à La Gazebo \\
\hline \multicolumn{2}{|l|}{ Porção/ Rendimento: uma pessoa } \\
\hline Ingredientes: & Modo de Preparo: \\
\hline$-220 \mathrm{~g}$ de filé mignon & \multirow{13}{*}{$\begin{array}{l}\text { - Rizoto: pré-cozinhar o arroz negro com o } \\
\text { vinho branco. Reservar. Puxar na manteiga } \\
\text { o alho, a cebola, o cogumelo picado, } \\
\text { acrescentar o arroz, o caldo de carne (já } \\
\text { preparado), o creme de leite e cozinhar até } \\
\text { o ponto "al dente". Finalizar com o } \\
\text { parmesão e a manteiga. } \\
\text { - Filét mignon: grelhar o filé na manteiga } \\
\text { com um fio de óleo de milho até o ponto } \\
\text { desejado. Reservar. Iniciar o molho, } \\
\text { dourando o azeite, depois acrescentar a } \\
\text { cebola, o vinho branco, a castanha picada e } \\
\text { finalizar com a manteiga e a salsinha. } \\
\text { Montar o prato com o filé grelhado, o } \\
\text { molho à La bourguignonne e o rizoto de } \\
\text { arroz negro. Decorar. }\end{array}$} \\
\hline - $100 \mathrm{~g}$ de manteiga & \\
\hline$-70 \mathrm{~g}$ de cebola & \\
\hline$-70 \mathrm{~g}$ de alho & \\
\hline - 50 g de castanha-de-caju em pedaços & \\
\hline - $70 \mathrm{~g}$ de azeite & \\
\hline - $70 \mathrm{~g}$ de vinho branco & \\
\hline - salsinha picada & \\
\hline - $80 \mathrm{~g}$ de arroz negro & \\
\hline - $100 \mathrm{ml} \mathrm{de} \mathrm{creme} \mathrm{de} \mathrm{leite} \mathrm{fresco}$ & \\
\hline - 100 g de cogumelo shimeji & \\
\hline - queijo parmesão ralado & \\
\hline & \\
\hline
\end{tabular}


Restaurante La Bússola

\begin{tabular}{|c|c|}
\hline \multicolumn{2}{|c|}{ Ficha Técnica de Preparo } \\
\hline $\begin{array}{l}\text { Tipo de Produto (Grupo): prato feito, prato } \\
\text { principal }\end{array}$ & Item: Rizoto de Bacalhau \\
\hline Porção/ Rendimento: duas pessoas & \multirow{14}{*}{$\begin{array}{l}\text { Modo de Preparo: } \\
\text { - Lave o bacalhau, corte em pedaços e } \\
\text { coloque numa tigela com } 2 \text { litros de água. } \\
\text { Deixe de molho na geladeira por } 36 \text { horas, } \\
\text { trocando a água } 5 \text { vezes. Coloque-o numa } \\
\text { panela com } 2 \text { litros de água e cozinhe até } \\
\text { ficar macio. Reserve a água do cozimento, } \\
\text { mantendo-a aquecida. Elimine a pele e as } \\
\text { espinhas do bacalhau, desfie e reserve. } \\
\text { Pique os pimentões em pedaços. Amasse } \\
\text { os dentes de alho. Reserve. Coloque numa } \\
\text { panela o azeite, o alho, a cebola e o } \\
\text { bacalhau desfiado. Leve ao fogo e refogue, } \\
\text { mexendo, até o bacalhau ficar levemente } \\
\text { dourado. Em seguida, adicione o arroz e } \\
\text { refogue. Junte o vinho branco e deixe } \\
\text { cozinhar, mexendo sem parar, raspando o } \\
\text { fundo e as laterais da panela, até não ter } \\
\text { mais líquido. Continue a cozinhar e, a } \\
\text { cada minuto, despeje 1/2 xícara de chá de } \\
\text { água do cozimento do bacalhau. Não pare } \\
\text { de mexer, raspando o fundo e as laterais } \\
\text { da panela até o arroz ficar al dente. Retire } \\
\text { do fogo, adicione a manteiga e mantenha a } \\
\text { panela tampada por } 3 \text { minutos antes de } \\
\text { servir. Decore com azeitonas pretas e } \\
\text { rodelas de ovos cozidos. }\end{array}$} \\
\hline Ingredientes: & \\
\hline $\begin{array}{l}\text { - duas xícaras de chá de arroz italiano } \\
\text { (arbóreo) }\end{array}$ & \\
\hline - 1/2 xícara de chá de vinho branco seco & \\
\hline - 400g de bacalhau do Porto & \\
\hline - 50g de pimentões verdes & \\
\hline - 50g de pimentões vermelhos & \\
\hline - $20 \mathrm{~g}$ de cebola ralada & \\
\hline - 2 dentes de alho & \\
\hline - 3 colheres de sopa de azeite de oliva & \\
\hline - 1 colher de sopa de manteiga & \\
\hline - 16 azeitonas pretas & \\
\hline-2 ovos cozidos & \\
\hline & \\
\hline
\end{tabular}


Restaurante Lagash

\begin{tabular}{|c|c|}
\hline \multicolumn{2}{|c|}{ Ficha Técnica de Preparo } \\
\hline Tipo de Produto (Grupo): prato feito & Item: Bacalhau Morisco \\
\hline \multicolumn{2}{|l|}{ Porção/ Rendimento: quatro pessoas } \\
\hline Ingredientes: & Modo de Preparo: \\
\hline - $1 \mathrm{~kg}$ de bacalhau & \multirow{15}{*}{$\begin{array}{l}\text { - Dessalgue o bacalhau, escorra. Passe para } \\
\text { a panela cubra com água e deixe ferver por } \\
10 \text { minutos sem tampar. Escorra, tire as } \\
\text { espinhas, o coro e separe em lâminas. } \\
\text { Triture o alho, o alecrim, o coentro, a } \\
\text { cebola em fatias, o sal e a pimenta. } \\
\text { Acrescente o azeite e forme uma leve pasta } \\
\text { e tempere as batatas já pré-cozidas e } \\
\text { cortadas em lâminas. Disponha em uma } \\
\text { assadeira e leve ao forno por } 15 \text { minutos. } \\
\text { Misture o bacalhau, o tomate cortado (sem } \\
\text { pele e sementes) e deixe assar por mais } 30 \\
\text { minutos em forno quente. Cozinhe o grão } \\
\text { de bico em separado. Descasque, tempere } \\
\text { com cebola e alho e sirva como } \\
\text { acompanhamento. }\end{array}$} \\
\hline - 500g de grão de bico & \\
\hline-6 tomates & \\
\hline - 4 dentes de alho & \\
\hline - 200g de nozes & \\
\hline - 100g de azeitonas pretas & \\
\hline - 100g de azeitonas verdes & \\
\hline - 300g de batatas & \\
\hline-3 cebolas & \\
\hline - 1 colher de café de alecrim & \\
\hline - 1 colher de café de coentro & \\
\hline - 1 ramo de salsa & \\
\hline - 2 colheres de mel & \\
\hline - 1 colher de café de pimenta-do-reino & \\
\hline - $100 \mathrm{ml}$ de azeite extra-virgem & \\
\hline
\end{tabular}


Restaurante Oliver

\begin{tabular}{|c|c|}
\hline \multicolumn{2}{|c|}{ Ficha Técnica de Preparo } \\
\hline Tipo de Produto (Grupo): prato principal & Item: Spaguetti de proscuitto de Parma \\
\hline \multicolumn{2}{|l|}{ Porção/ Rendimento: uma pessoa } \\
\hline Ingredientes: & Modo de Preparo: \\
\hline - 100g de espaguete & \multirow{13}{*}{$\begin{array}{l}\text { - Cozinhe o espaguete durante } 8 \text { minutos e } \\
\text { reserve. Numa frigideira, aqueça o azeite e } \\
\text { em seguida adicione o alho e a cebola, } \\
\text { depois acrescente os aspargos. Adicione o } \\
\text { creme de leite e deixe reduzir, acrescente } \\
\text { os dois queijos e deixe reduzir por mais } 30 \\
\text { segundos. Tempere com a pimenta e a } \\
\text { sálvia. Coloque o espaguete em um prato } \\
\text { fundo para massa, cubra com o molho de } \\
\text { aspargos e distribua o proscuitto di Parma } \\
\text { sobre o prato. Se for colocar sal, faça } \\
\text { somente no final, pois os queijos e o } \\
\text { proscuitto já têm sal suficiente e bom } \\
\text { apetite. }\end{array}$} \\
\hline - 70g de proscuitto di Parma & \\
\hline - 50g de aspargos frescos & \\
\hline - 30g de cogumelos frescos & \\
\hline - 30g de queijo provolone & \\
\hline - 30g de queijo parmesão & \\
\hline - $150 \mathrm{~g}$ de creme de leite fresco & \\
\hline - 5g de sálvia & \\
\hline - $3 \mathrm{~g}$ de pimenta-do-reino & \\
\hline - 5g de cebola & \\
\hline - 3g de alho & \\
\hline - 40g de azeite extra-virgem & \\
\hline & \\
\hline
\end{tabular}


Restaurante Patuá

\begin{tabular}{|c|c|}
\hline \multicolumn{2}{|c|}{ Ficha Técnica de Preparo } \\
\hline Tipo de Produto (Grupo): prato feito & Item: Filé Gourmet \\
\hline \multicolumn{2}{|l|}{ Porção/ Rendimento: quatro pessoas } \\
\hline Ingredientes: & Modo de Preparo: \\
\hline - filé: & \multirow{25}{*}{$\begin{array}{l}\text { - Tempere o filé e passe as laterais no } \\
\text { tomilho. Faça um medalhão com o } \\
\text { presunto de Parma e prenda com palitos. } \\
\text { Grelhe o filé no ponto desejado. Para o } \\
\text { purê, cozinhe a banana da terra em água } \\
\text { fervente. Após cozida, retire a casca e } \\
\text { amasse grosseiramente a banana. Refogue } \\
\text { a cebola na manteiga e adicione e banana. } \\
\text { Tempere a gosto e adicione o leite até ficar } \\
\text { na consistência correta. Para o salteado, } \\
\text { refogue o alho e a cebola. Adicione o } \\
\text { palmito e os cogumelos e refogue até } \\
\text { ficarem macios. Coloque todos os } \\
\text { ingredientes do molho de tamarindo numa } \\
\text { panela e deixe ferver. Quando ferver, } \\
\text { reduzir em fogo baixo até ficar espesso, } \\
\text { mexendo de vez em quando. Bater no } \\
\text { liquidificador. } \\
\text { - Montagem: Coloque o purê de banana da } \\
\text { terra e adicione o salteado de palmito e } \\
\text { cogumelos sobre este. Retire os palitos do } \\
\text { filé e acrescente duas porções por prato, } \\
\text { regando com o molho de tamarindo. } \\
\text { Decore com dois ramos de cebolete. }\end{array}$} \\
\hline - $800 \mathrm{~g}$ de filé mignon ( 8 porções de $100 \mathrm{~g}$ ) & \\
\hline - 200g de presunto de Parma & \\
\hline - 3 colheres de sopa de tomilho fresco & \\
\hline - sal a gosto & \\
\hline - purê de banana da terra: & \\
\hline - $1 \mathrm{~kg}$ de banana da terra madura & \\
\hline - $100 \mathrm{ml}$ de leite & \\
\hline - 1 ou 2 colheres de açúcar & \\
\hline - sal a gosto & \\
\hline - 1 pitada de canela & \\
\hline - 1 colher de sopa de manteiga & \\
\hline - 1 colher de sopa de cebola picada & \\
\hline - salteado de palmito: & \\
\hline - 3 palmitos cortados em tiras finas & \\
\hline - $150 \mathrm{~g}$ de shimeji & \\
\hline - 100g de shitake cortado em tiras finas & \\
\hline - 150g de cogumelo paris cortado em tiras & \\
\hline - 2 colheres de sopa de manteiga & \\
\hline - 2 colheres de cebola picada & \\
\hline - 2 dentes de alho amassados & \\
\hline - molho de tamarindo: & \\
\hline - 200g de polpa de tamarindo & \\
\hline - $300 \mathrm{ml}$ de água & \\
\hline - 100g de açúcar & \\
\hline
\end{tabular}


Restaurante Peixe na Rede

\begin{tabular}{|c|c|}
\hline \multicolumn{2}{|c|}{ Ficha Técnica de Preparo } \\
\hline $\begin{array}{l}\text { Tipo de Produto (Grupo): prato feito, prato } \\
\text { principal }\end{array}$ & $\begin{array}{l}\text { Item: Filé de tilápia ao molho de camarão } \\
\text { e caju }\end{array}$ \\
\hline Porção/ Rendimento: duas pessoas & \multirow[b]{2}{*}{ Modo de Preparo: } \\
\hline Ingredientes: & \\
\hline - 3 colheres de sopa de azeite-de-dendê & \multirow{20}{*}{$\begin{array}{l}\text { - Tempere o peixe com o sumo do limão, } \\
\text { sal, pimenta-do-reino e cominho. Reserve } \\
\text { por } 2 \text { horas antes do preparo do prato. Em } \\
\text { uma caçarola ou panela de barro aquecida, } \\
\text { doure o alho no azeite-de-dendê. } \\
\text { Acrescente a cebola e deixe murchar. } \\
\text { Coloque pimentão, o tomate picado e a } \\
\text { folha de louro. Refogue até o tomate } \\
\text { desmanchar. Coloque as postas de peixe } \\
\text { no refogado, acrescente o leite de coco, o } \\
\text { sumo dos cajus (furar os cajus com um } \\
\text { garfo e espremer entre os dedos, retirando } \\
\text { o sumo, reservar o bagaço), a pimenta e } \\
\text { corrigir o sal. Corte o caju em rodelas e } \\
\text { acrescente no cozido. Cozinhe por } 10 \\
\text { minutos. Por último, coloque os camarões, } \\
\text { o coentro, a salsa, a castanha-de-caju } \\
\text { (quebrar parte da castanha em pedaços } \\
\text { pequenos e deixar a outra parte pela } \\
\text { metade). Regue com azeite. Verifique e } \\
\text { corrija o sal após uns } 5 \text { minutos de } \\
\text { cozimento. Sirva com arroz branco. É } \\
\text { importante que todos os ingredientes } \\
\text { sejam frescos. }\end{array}$} \\
\hline - 2 colheres de sopa de coentro picado & \\
\hline - 3 colheres de sopa de azeite de oliva & \\
\hline - 1 colher de sopa de salsa picada & \\
\hline - $1 \mathrm{~kg}$ de filé de tilápia & \\
\hline - $1 / 2 \mathrm{~kg}$ de camarão rosa grande & \\
\hline - 5 tomates maduros sem pele e semente & \\
\hline - 1 lata de molho de tomate & \\
\hline - 3 dentes de alho socados com sal & \\
\hline - 100g de castanha-de-caju inteiras & \\
\hline - 1 pimenta dedo-de-moça picada & \\
\hline - 1 pitada de pimenta-do-reino & \\
\hline - 1 pimentão pequeno picado & \\
\hline - 1 cebola média picada & \\
\hline - 1 pitada de cominho & \\
\hline - $250 \mathrm{ml}$ de leite de coco & \\
\hline - 1 folha de louro & \\
\hline - sal a gosto & \\
\hline-3 cajus & \\
\hline - sumo de $1 / 2$ limão & \\
\hline
\end{tabular}


Restaurante Sonoma Steak

\begin{tabular}{|c|c|}
\hline \multicolumn{2}{|c|}{ Ficha Técnica de Preparo } \\
\hline $\begin{array}{l}\text { Tipo de Produto (Grupo): prato feito, prato } \\
\text { principal }\end{array}$ & Item: Lombo de cordeiro com chutney \\
\hline Porção/ Rendimento: uma pessoa & \\
\hline Ingredientes: & Modo de Preparo: \\
\hline - 200g de lombo de cordeiro & - Tempere o lombo com sal, pimenta e \\
\hline$-5 \mathrm{~g}$ de sal & tomilho e coloque na grelha com um \\
\hline - 5 g de pimenta-do-reino & pouco de azeite. Deve ser servido ao \\
\hline$-5 \mathrm{~g}$ de tomilho fresco & ponto. Para o chutney, em uma panela, \\
\hline$-10 \mathrm{ml}$ de azeite fresco & faça um caramelo com o vinagre e o \\
\hline$-30 \mathrm{~g}$ de cebola & açúcar. Acrescente a cebola picada e por \\
\hline - $30 \mathrm{ml} \mathrm{de} \mathrm{vinagre}$ & último as frutas picadas. Cozinhe até que \\
\hline$-15 \mathrm{~g}$ de murici & fique em ponto de geléia. Cozinhe a \\
\hline - 10 g de açúcar & quinoa com $200 \mathrm{ml}$ de água em fogo \\
\hline - 100 g de quinoa & baixo, com azeite e sal. Quando estiver \\
\hline-20 g de baru & cozida, adicione cebolete picada e baru \\
\hline - $5 \mathrm{~g}$ de cebolete & $\begin{array}{l}\text { triturado sem casca. } \\
\text { - Montagem: corte o lombo em fatias de } 2 \\
\text { cm. Coloque o chutney em um potinho a } \\
\text { parte e a quinoa ao lado da carne e sirva. }\end{array}$ \\
\hline
\end{tabular}


Restaurante Unanimitá

\begin{tabular}{|c|c|}
\hline \multicolumn{2}{|c|}{ Ficha Técnica de Preparo } \\
\hline $\begin{array}{l}\text { Tipo de Produto (Grupo): prato feito, prato } \\
\text { principal }\end{array}$ & Item: Filé Pirenópolis \\
\hline Porção/ Rendimento: duas pessoas & \\
\hline Ingredientes: & Modo de Preparo: \\
\hline - 500g de filé mignon & - Temperar e grelhar o filé em uma \\
\hline - sal e pimenta-do-reino a gosto & frigideira pré-aquecida com manteiga e \\
\hline - $50 \mathrm{~g}$ de manteiga & flambar com conhaque. Para o pesto junte \\
\hline - $50 \mathrm{ml}$ de conhaque & todos os ingredientes em uma vasilha e \\
\hline - pesto: & misture muito bem, pode ser em um \\
\hline - $500 \mathrm{ml}$ de azeite extra-virgem & processador também. Cozinhe o pene "al \\
\hline - $100 \mathrm{~g}$ de baru picado & dente" e misture com o pesto, os tomates e \\
\hline - 150 g de parmesão ralado & a mussarela de búfala. \\
\hline $\begin{array}{l}\text { - } 1 \text { maço de manjericão desfolhado e } \\
\text { picado }\end{array}$ & $\begin{array}{l}\text { - Montagem: Coloque o filé nas laterais de } \\
\text { uma travessa, cubra com um pouco de }\end{array}$ \\
\hline - $80 \mathrm{~g}$ de alho picado & pesto, no centro coloque o penne. Decore e \\
\hline - $100 \mathrm{~g}$ de queijo pecorino ralado & sirva. \\
\hline - penne: & \\
\hline - $250 \mathrm{~g}$ de penne rigate cru & \\
\hline - $300 \mathrm{ml} \mathrm{de} \mathrm{molho} \mathrm{pesto}$ & \\
\hline - 4 tomates concassê & \\
\hline $\begin{array}{l}\text { - } 4 \text { bolinhas de mussarela de búfala } \\
\text { cortada }\end{array}$ & \\
\hline
\end{tabular}


Restaurante Villa Tevere

\begin{tabular}{|c|c|}
\hline \multicolumn{2}{|c|}{ Ficha Técnica de Preparo } \\
\hline Tipo de Produto (Grupo): prato principal & Item: Rizoto Brasiliano \\
\hline Porção/ Rendimento: duas pessoas & \\
\hline Ingredientes: & Modo de Preparo: \\
\hline - 150 g de arroz arbóreo & - colocar um pouco de óleo em uma panela \\
\hline - 150 g de feijão verde & e fritar o bacon até ficar crocante. Escorrer \\
\hline $\begin{array}{l}\text { - } 200 \text { g de carne de charque dessalgada e } \\
\text { cozida em pressão por } 30 \text { minutos }\end{array}$ & $\begin{array}{l}\text { em papel. Levar ao fogo a gordura do } \\
\text { bacon com a cebola e o alho ( } 1 \text { colher de }\end{array}$ \\
\hline $\begin{array}{l}\text { - } 250 \text { g de abóbora verde kabutiá } \\
\text { descascada e cortada em cubos médios }\end{array}$ & $\begin{array}{l}\text { cada) e refogar o feijão. Juntar o louro e a } \\
\text { pimenta em grão e um pouco de sal e }\end{array}$ \\
\hline $\begin{array}{l}250 \mathrm{~g} \text { de bacom cortado e fatiado em } \\
\text { pedaços médios }\end{array}$ & $\begin{array}{l}\text { cozinhar com o caldo de carne até ficar } \\
\text { macio, porém firme. Refogar a abóbora em }\end{array}$ \\
\hline $\begin{array}{l}\text { - } 2 \text { litros de caldo de carne reduzido em } \\
70 \%\end{array}$ & $\begin{array}{l}\text { manteiga com } 1 \text { colher de cebola e } 1 \text { de } \\
\text { alho. Colocar caldo de carne somente para }\end{array}$ \\
\hline - $100 \mathrm{ml}$ de óleo vegetal & cozinhar, temperar com sal e juntar com o \\
\hline - $200 \mathrm{ml}$ de manteiga de garrafa derretida & feijão. Em uma panela, colocar 2 colheres \\
\hline - $100 \mathrm{ml}$ de cachaça & de cebola e 1 de alho, óleo e acrescentar o \\
\hline - cebolinha picada a gosto & arroz. Flambar com a cachaça e ir \\
\hline - 4 colheres de sopa de cebola processada & acrescentado aos poucos o caldo de carne, \\
\hline - 4 colheres de sopa de alho picado & mexendo sempre até que o rizoto fique \\
\hline - 2 folhas de louro & quase cozido. Separadamente, refogar em \\
\hline - 6 grãos de pimenta preta & manteiga de garrafa 1 colher de cebola \\
\hline - sal e pimenta-do-reino & juntar a carne de charque desfiada, juntar a \\
\hline - $150 \mathrm{~g}$ de queijo coalho & abóbora e o feijão. Cortar uma tampa na \\
\hline - 1 abóbora kabutiá de tamanho médio & $\begin{array}{l}\text { abóbora, abrir e limpar. Cozinhar a } \\
\text { abóbora em água temperada com sal, } \\
\text { tomando cuidado para que a mesma } \\
\text { cozinhe sem quebrar. Aquecer bem o } \\
\text { refogado de feijão e juntá-lo ao arroz. } \\
\text { Acrescentar queijo ralado, o bacon } \\
\text { crocante e a cebolinha picada. Colocar na } \\
\text { abóbora, decorar e servir. }\end{array}$ \\
\hline
\end{tabular}


PLANILHA - AVALIAÇÃO QUALITATIVA DAS PREPARAÇÕES DOS CARDÁPIOS OFERTADOS NA 4ª EDIÇÃO DO FESTIVAL BRASIL SABOR BRASÍLIA (2007)

\begin{tabular}{|c|c|c|c|c|c|}
\hline ITEM/ RESTAURANTE & PREPARAÇÃO & TÉCNICA DE COCÇÃO & COR & PRESENÇA DE HORTALIÇAS & INGREDIENTES COM GORDURA \\
\hline \multicolumn{6}{|l|}{ 1) BABEL } \\
\hline PRATO PRINCIPAL & ESCALOPE DE FILÉ MIGNON & GRELHAR & MARROM/VERDE & NÃO & MANTEIGA \\
\hline GUARNIÇÃO & RISOTO COM CASTANHA & COZINHAR & AMARELO & BARU & BARU \\
\hline \multicolumn{6}{|l|}{ ENTRADA } \\
\hline \multicolumn{6}{|l|}{ ACOMPANHAMENTO } \\
\hline \multicolumn{6}{|l|}{ SOBREMESA } \\
\hline \multicolumn{6}{|l|}{ 2) AZULEJARIA } \\
\hline PRATO PRINCIPAL & FILÉ MIGNON & GRELHAR/ASSAR & MARROM/BEGE & NÃO & CRÈME DE LEITE/MANTEIGA \\
\hline GUARNIÇÃO & BATATAS COM AZEITE & COZINHAR/ASSAR & AMARELO & BATATA & AZEITE DE OLIVA \\
\hline \multicolumn{6}{|l|}{ ENTRADA } \\
\hline \multicolumn{6}{|l|}{ ACOMPANHAMENTO } \\
\hline \multicolumn{6}{|l|}{ SOBREMESA } \\
\hline \multicolumn{6}{|l|}{ 3) CALAF } \\
\hline PRATO PRINCIPAL & BISTECA DE CORDEIRO & GRELHAR & MARROM & NÃO & NÃO \\
\hline GUARNIÇÃO & BATATA E CEBOLA ASSADAS & ASSAR & AMARELO & BATATA E CEBOLA & AZEITE DE OLIVA \\
\hline \multicolumn{6}{|l|}{ ENTRADA } \\
\hline ACOMPANHAMENTO & ARROZ SIMPLES & COZINHAR & BRANCO & NÃO & \\
\hline \multicolumn{6}{|l|}{ SOBREMESA } \\
\hline \multicolumn{6}{|l|}{ 4) BSBS GRILL } \\
\hline PRATO PRINCIPAL & T-BONE BOVINO & GRELHAR & MARROM & NÃO & NÃO \\
\hline GUARNIÇÃO & FAROFA DE OVOS & REFOGAR/FRITAR & AMARELO & CEBOLINHA VERDE & ÓLEO \\
\hline \multicolumn{6}{|l|}{ ENTRADA } \\
\hline ACOMPANHAMENTO & ARROZ BIRO BIRO & REFOGAR/COZINHAR & BRANCO & CEBOLINHA VERDE & LINGÜIÇA SUÍNA/BATATA PALHA \\
\hline SOBREMESA & & & & & \\
\hline
\end{tabular}




\begin{tabular}{|c|c|c|c|c|c|}
\hline \multicolumn{6}{|l|}{ 5) ANTIQUÁRIO } \\
\hline PRATO PRINCIPAL & ESCONDIDINHO DE CAMARÃO & COZINHAR & BEGE & ALHO PORÓ, SALSÃO, INHAME & LEITE DE COCO/QUEIJO \\
\hline GUARNIÇÃO & CREME DE INHAME & COZINHAR & BRANCO & ALHO PORÓ, SALSÃO, INHAME & CREME DE LEITE/QUEIJOS \\
\hline \multicolumn{6}{|l|}{ ENTRADA } \\
\hline \multicolumn{6}{|l|}{ ACOMPANHAMENTO } \\
\hline \multicolumn{6}{|l|}{ SOBREMESA } \\
\hline \multicolumn{6}{|l|}{ 6) CASSIS } \\
\hline \multicolumn{6}{|l|}{ PRATO PRINCIPAL } \\
\hline \multicolumn{6}{|l|}{ GUARNIÇÃO } \\
\hline ENTRADA & TACO WRAP COMBO & REFOGAR/COZINHAR & BEGE & ALFACE/ABACATE & QUEIJO CHEDAR \\
\hline \multicolumn{6}{|l|}{ ACOMPANHAMENTO } \\
\hline \multicolumn{6}{|l|}{ SOBREMESA } \\
\hline \multicolumn{6}{|l|}{ 7) CÉST SI BOM } \\
\hline \multicolumn{6}{|l|}{ PRATO PRINCIPAL } \\
\hline \multicolumn{6}{|l|}{ GUARNIÇÃO } \\
\hline ENTRADA & CREPE DE SALMÃO & GRELHAR/REFOGAR & AMARELO & NÃO & REQUEIJÃO/MANTEIGA \\
\hline \multicolumn{6}{|l|}{ ACOMPANHAMENTO } \\
\hline \multicolumn{6}{|l|}{ SOBREMESA } \\
\hline \multicolumn{6}{|l|}{ 8) CONF. FRANCESA } \\
\hline \multicolumn{6}{|l|}{ PRATO PRINCIPAL } \\
\hline \multicolumn{6}{|l|}{ GUARNIÇÃO } \\
\hline \multicolumn{6}{|l|}{ ENTRADA } \\
\hline \multicolumn{6}{|l|}{ ACOMPANHAMENTO } \\
\hline SOBREMESA & MERENGUE RECHEADO & ASSAR & BRANCO/MARROM & NÃO & CHOCOLATE/CREME DE LEITE \\
\hline \multicolumn{6}{|c|}{ 9) CONFRARIA DO CAMARÃO } \\
\hline PRATO PRINCIPAL & ESPAGUETE COM CAMARÃO & REFOGAR/COZINHAR & AMARELO & NÃO & CREME DE LEITE/AZEITE \\
\hline \multicolumn{6}{|l|}{ GUARNIÇÃO } \\
\hline \multicolumn{6}{|l|}{ ENTRADA } \\
\hline \multicolumn{6}{|l|}{ ACOMPANHAMENTO } \\
\hline SOBREMESA & & & & & \\
\hline
\end{tabular}




\begin{tabular}{|c|c|c|c|c|c|}
\hline \multirow{2}{*}{\multicolumn{6}{|c|}{\begin{tabular}{|l|} 
10) CREPE AU CHOCOLAT \\
PRATO PRINCIPAL
\end{tabular}}} \\
\hline & & & & & \\
\hline \multicolumn{6}{|l|}{ GUARNIÇÃO } \\
\hline ENTRADA & CREPE DE ALCACHOFRA & REFOGAR/GRELHAR & AMARELO & ALCACHOFRA/TOMATE & AZEITE/QUEIJOS \\
\hline \multicolumn{6}{|l|}{ ACOMPANHAMENTO } \\
\hline \multicolumn{6}{|l|}{ SOBREMESA } \\
\hline \multicolumn{6}{|l|}{ 11) DON PEPE } \\
\hline PRATO PRINCIPAL & LOMBO DE CORDEIRO & COZINHAR & MARROM & SALSÃO/ALHO PORÓ/CENOURAS & NÃO \\
\hline GUARNIÇÃO & POLENTA DE TARTUFO & COZINHAR & AMARELO & NÃO & QUEIJO \\
\hline \multicolumn{6}{|l|}{ ENTRADA } \\
\hline \multicolumn{6}{|l|}{ ACOMPANHAMENTO } \\
\hline \multicolumn{6}{|l|}{ SOBREMESA } \\
\hline \multicolumn{6}{|l|}{ 12) DUDU CAMARGO } \\
\hline PRATO PRINCIPAL & ROBALO & GRELHAR & BEGE & NÃO & BARU \\
\hline \multicolumn{6}{|l|}{ GUARNIÇÃO } \\
\hline \multicolumn{6}{|l|}{ ENTRADA } \\
\hline ACOMPANHAMENTO & ARROZ COM CAJU & COZINHAR & BRANCO & NÃO & CREME DE LEITE \\
\hline \multicolumn{6}{|l|}{ SOBREMESA } \\
\hline \multicolumn{6}{|l|}{ 13) EL PASO TEXAS } \\
\hline \multicolumn{6}{|l|}{ PRATO PRINCIPAL } \\
\hline \multicolumn{6}{|l|}{ GUARNIÇÃO } \\
\hline ENTRADA & TACOS DE CAMARÕES & FRITAR/GRELHAR & AMARELO/VERDE & ALFACE/ABACATE/TOMATE & QUEIJO/CREME DE LEITE \\
\hline \multicolumn{6}{|l|}{ ACOMPANHAMENTO } \\
\hline \multicolumn{6}{|l|}{ SOBREMESA } \\
\hline \multicolumn{6}{|l|}{ 14) ESQUINA MINEIRA } \\
\hline PRATO PRINCIPAL & FEIJOADA DE FRUTOS DO MAR & REFOGAR/COZINHAR & AMARELO & PIMENTÃO/TOMATE & AZEITE-DE-DENDÊ/LEITE DE COCO \\
\hline \multicolumn{6}{|l|}{ GUARNIÇÃO } \\
\hline ENTRADA & & & & & \\
\hline
\end{tabular}




\begin{tabular}{|c|c|c|c|c|c|}
\hline ACOMPANHAMENTO & ARROZ BRANCO & COZINHAR & BRANCO & NÃO & ÓLEO \\
\hline SOBREMESA & & & & & \\
\hline \multicolumn{6}{|l|}{ 15) FRED } \\
\hline PRATO PRINCIPAL & CARRÉ SUÍNO DEFUMADO & GRELHAR/COZINHAR & MARROM & CEBOLA & MANTEIGA \\
\hline GUARNIÇÃO & PURÊ DE BATATAS & COZINHAR & AMARELO & BATATA & MANTEIGA \\
\hline \multicolumn{6}{|l|}{ ENTRADA } \\
\hline \multicolumn{6}{|l|}{ ACOMPANHAMENTO } \\
\hline \multicolumn{6}{|l|}{ SOBREMESA } \\
\hline \multicolumn{6}{|l|}{ 16) GAZEBO } \\
\hline PRATO PRINCIPAL & FILÉ MINGNON & GRELHAR & MARROM/AMARELO & CEBOLA/SALSINHA & MANTEIGA/CASTANHA \\
\hline \multicolumn{6}{|l|}{ GUARNIÇÃO } \\
\hline \multicolumn{6}{|l|}{ ENTRADA } \\
\hline ACOMPANHAMENTO & ARROZ NEGRO & COZINHAR & PRETO & COGUMELO SHIMEJI & CREME DE LEITE/PARMESÃO \\
\hline \multicolumn{6}{|l|}{ SOBREMESA } \\
\hline \multicolumn{6}{|l|}{ 17) LA BÚSSOLA } \\
\hline PRATO PRINCIPAL & RISOTO DE BACALHAU & COZINHAR & AMARELO/PRETO & PIMENTÃO/AZEITONA & MANTEIGA/AZEITE \\
\hline \multicolumn{6}{|l|}{ GUARNIÇÃO } \\
\hline \multicolumn{6}{|l|}{ ENTRADA } \\
\hline \multirow{2}{*}{\multicolumn{6}{|c|}{$\begin{array}{l}\text { ACOMPANHAMENTO } \\
\text { SOBREMESA }\end{array}$}} \\
\hline & & & & & \\
\hline \multicolumn{6}{|l|}{ 18) LAGASH } \\
\hline PRATO PRINCIPAL & BACALHAU MORISCO & COZINHAR/ASSAR & BEGE & BATATA & AZEITE/NOZES \\
\hline GUARNIÇÃO & GRÃO DE BICO & COZINHAR & AMARELO & CEBOLA & NÃO \\
\hline \multicolumn{6}{|l|}{ ENTRADA } \\
\hline \multicolumn{6}{|l|}{ ACOMPANHAAMENTO } \\
\hline \multicolumn{6}{|l|}{ SOBREMESA } \\
\hline \multicolumn{6}{|l|}{ 19) OLIVER } \\
\hline PRATO PRINCIPAL & SPAGUETTI DE PARMA & COZINHAR/REFOGAR & AMARELO/VERMELHO & ASPARGO/COGUMELO & AZEITE/CREME DE LEITE/QUEIJOS \\
\hline \multicolumn{6}{|l|}{ GUARNIÇÃO } \\
\hline ENTRADA & & & & & \\
\hline
\end{tabular}




\begin{tabular}{|c|c|c|c|c|c|}
\hline \multicolumn{6}{|l|}{ ACOMPANHAMENTO } \\
\hline SOBREMESA & & & & & \\
\hline \multicolumn{6}{|l|}{ 20) PATUÁ } \\
\hline PRATO PRINCIPAL & FILÉ MINGNOM & GRELHAR & MARROM & NÃO & PRESUNTO DE PARMA \\
\hline GUARNIÇÃO & PURÊ DE BANANA DA TERRA & COZINHAR & AMARELO/BEGE & BANANA/PALMITO/COGUMELOS & MANTEIGA \\
\hline \multicolumn{6}{|l|}{ ENTRADA } \\
\hline \multicolumn{6}{|l|}{ ACOMPANHAMENTO } \\
\hline \multicolumn{6}{|l|}{ SOBREMESA } \\
\hline \multicolumn{6}{|l|}{ 21) PEIXE NA REDE } \\
\hline PRATO PRINCIPAL & FILÉ DE TILÁPIA COM CAMARÕES & GRELHAR/COZINHAR & AMARELO & TOMATE/PIMENTÃO/CEBOLA & DENDÊ/LEITE DE COCO/CASTANHA \\
\hline \multicolumn{6}{|l|}{ GUARNIÇÃO } \\
\hline \multicolumn{6}{|l|}{ ENTRADA } \\
\hline ACOMPANHAMENTO & ARROZ BRANCO & COZINHAR & BRANCO & NÃO & ÓLEO \\
\hline \multicolumn{6}{|l|}{ SOBREMESA } \\
\hline \multicolumn{6}{|l|}{ 22) SONOMA STEAK } \\
\hline PRATO PRINCIPAL & LOMBO DE CORDEIRO & GRELHAR & MARROM & NÃO & NÃO \\
\hline GUARNIÇÃO & QUINOA COM BARU/CHUTNEY & COZINHAR & BEGE/AMARELO & MURICI & BARU \\
\hline \multicolumn{6}{|l|}{ ENTRADA } \\
\hline \multicolumn{6}{|l|}{ ACOMPANHAMENTO } \\
\hline \multicolumn{6}{|l|}{ SOBREMESA } \\
\hline \multicolumn{6}{|l|}{ 23) UNANIMITÁ } \\
\hline PRATO PRINCIPAL & FILE MINGNON & GRELHAR & MARROM & NÃO & MANTEIGA \\
\hline GUARNIÇÃO & PENNE & COZINHAR & BEGE & MANJERICÃO/TOMATE & AZEITE/BARU/QUEIJOS \\
\hline \multicolumn{6}{|l|}{ ENTRADA } \\
\hline \multicolumn{6}{|l|}{ ACOMPANHAMENTO } \\
\hline \multicolumn{6}{|l|}{ SOBREMESA } \\
\hline \multicolumn{6}{|l|}{ 24) VILLA TEVERE } \\
\hline PRATO PRINCIPAL & RISOTO BRASILIANO & COZINHAR & BRANCO/LARANJA & ABÓBORA VERDE E KABUTIÁ & BACON/MANTEIGA DE GARRAFA \\
\hline GUARNIÇÃO & & & & & \\
\hline
\end{tabular}




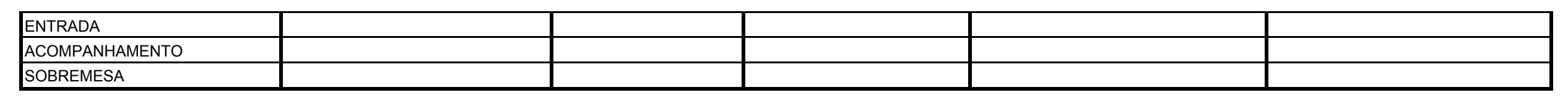

\begin{tabular}{|l|l|l|l|l|l|}
\hline 25) WERNER & & & & \\
\hline PRATO PRINCIPAL & MEDALHÕES DE FILÉ MIGNON & GRELHAR & MARROM/NERDE & MANJERICÃO/RÚCULA \\
\hline GUARNIÇÃO & & & & & \\
\hline ENTRADA & & & & & \\
\hline ACOMPANHAMENTO & ARROZ CREMOSO & COZINHAR & BRANCO/AMARELO & CARICA/ABÓBORA VERDE \\
\hline SOBREMESA & & & & & CREME DE LEITE/CREAM CHEESE \\
\hline
\end{tabular}




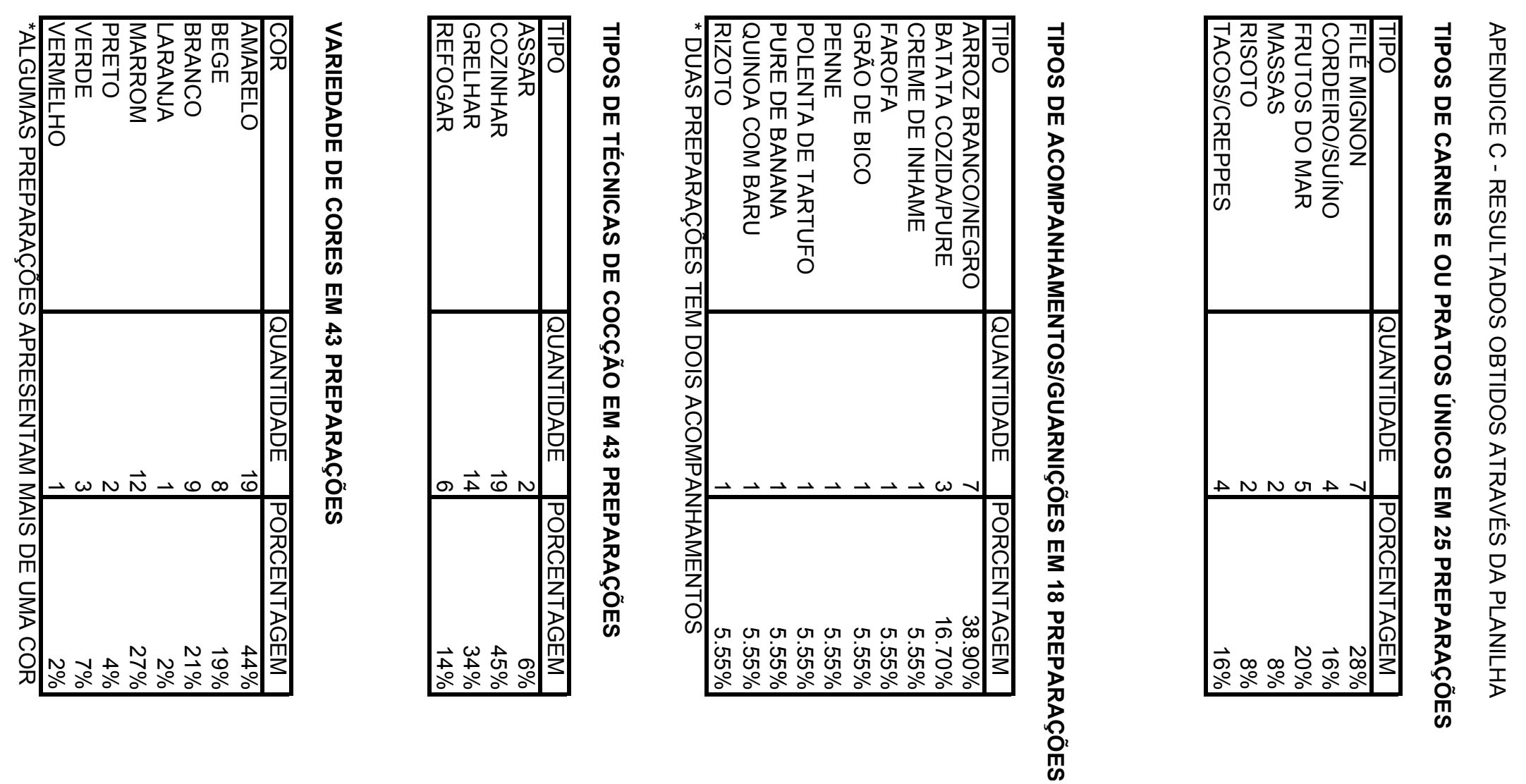

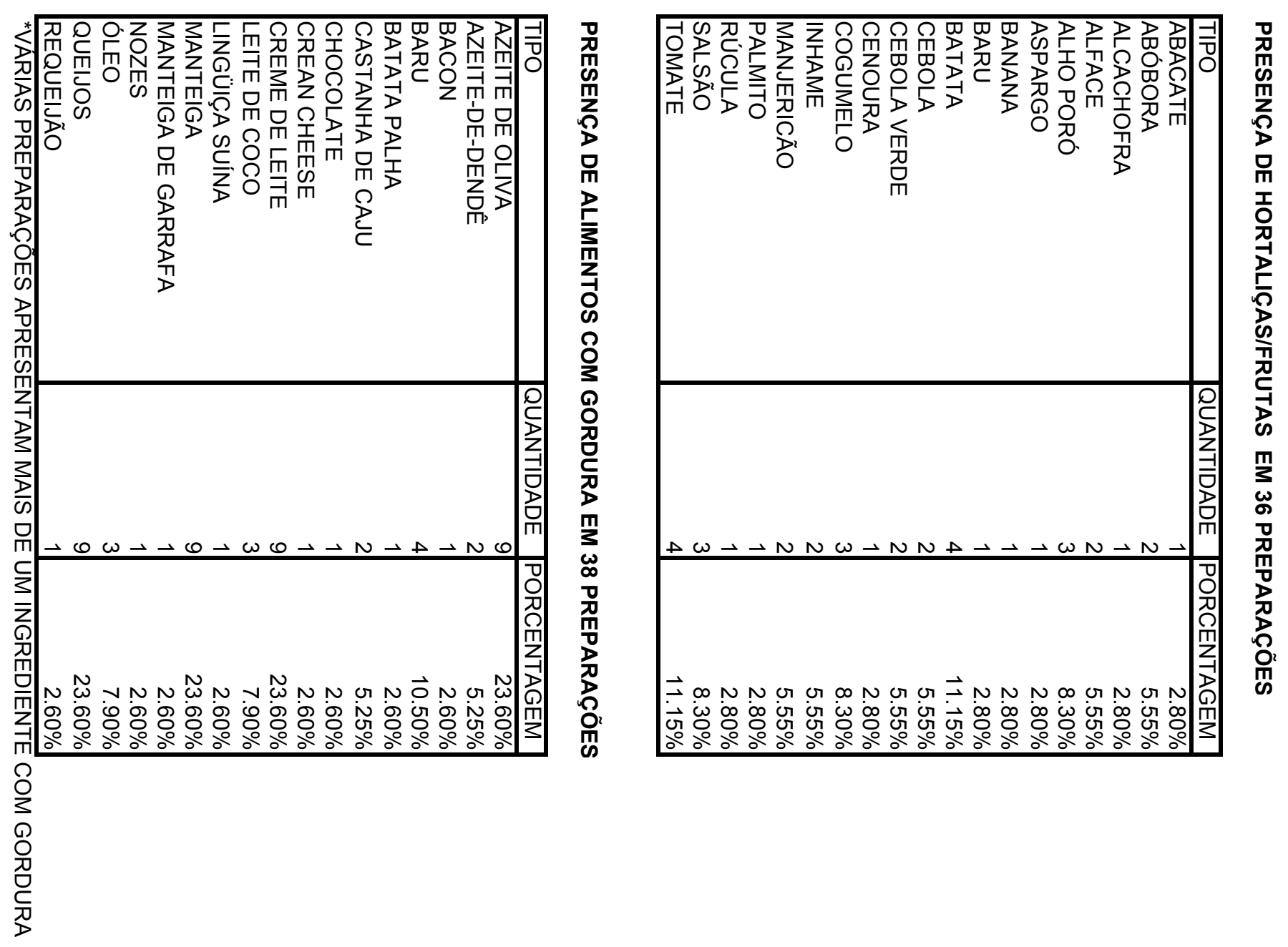